\title{
BARTOLOMÉ FERNÁNDEZ LECHUGA Y EL CLAUSTRO PROCESIONAL DE SAN MARTÍN PINARIO EN SANTIAGO DE COMPOSTELA
}

\author{
por \\ ALFREDO VIGO TRASANCOS \\ "La Abadia de San Martín está en el otro ex- \\ tremo de la ciudad; alli se comienza a alzar \\ un hermosísimo alojamiento para los religio- \\ sos, y todo eso reunido hace de Compostela \\ una de las más grandes, de las más ricas y de \\ las más hermosas ciudades de España".
}

(A Jouvin, 1672)

De entre todas las realizaciones arquitectónicas que se acometieron en Compostela a lo largo del siglo XVII, con la sola excepción de la Torre del Reloj remodelada por Andrade y convertida de hecho en todo un símbolo de la Ciudad Apostólica, el Claustro Procesional de San Martín Pinario, también llamado Reglar o de la Portería, es acaso la obra más importante, aunque sólo sea por lo magnífico y singular que resulta su diseño estructural en comparación con otros que también se realizaron en empresas de las mismas características (Fig. 1). Que yo sepa, nada hay ni en España ni en la Europa de su tiempo que se le pueda comparar, lo que quiere decir que, como claustro, bien puede considerarse una pieza excepcional, casi una rareza arquitectónica y, por consiguiente, una obra que, además de extraña, es un único dentro de su especie'. Sólo por eso, bien merecía haber

1 "Auténtico hito en la arquitectura española" lo considera con toda justicia BUSTAMANTE, 48. 


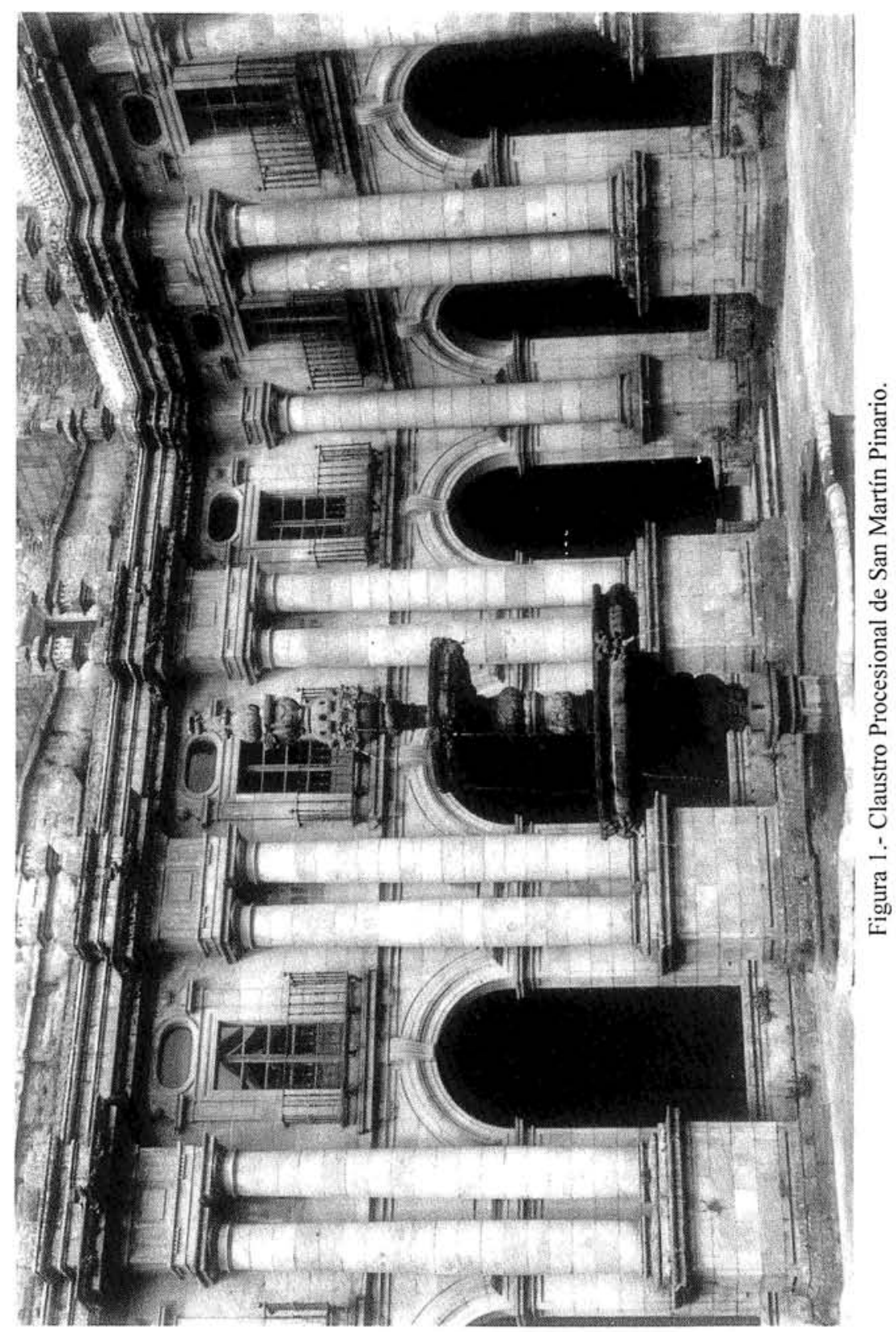


tenido más eco y proyección y aún incluso mejor fortuna crítica. Y sin embargo, pese a ello, tal vez por su localización excéntrica en un territorio periférico como era entonces Galicia, o porque a ello sumaba su condición de "arquitectura de interior" oculta a la mirada de la mayoría de los viajeros, lo cierto es que casi pasó desapercibida e incluso fue blanco de las críticas cuando, tiempo después, se lo empezó a conocer y a valorar.

A este respecto, pienso por ejemplo que fue poco afortunado el frío comentario que en su día le dedicó Murguía al considerarlo "de muy buen aire" pero de peor gusto que el segundo claustro que también poseía San Martín como era el llamado de las Oficinas ${ }^{2}$, que ciertamente es una obra de interés pero sin duda de tono más discreto y de categoría muy inferior. Mas a este juicio podríamos añadir el más injusto que le dedicó el eminente hispanista George Kubler que no conforme con considerarlo una obra infeliz y de poco talento, se permitía el lujo de atribuirla al siglo XVIII y a un autor que nada o poco tenía que ver con él ${ }^{3}$. Por suerte, junto a opiniones tan adversas, hubo también otros comentarios más positivos. Y en este sentido es importante la opinión que le dedicó el francés Alexandre de Laborde en 1806 al señalar que "el monasterio de San Martín" le parecía "respetable por su antigüedad y buen gusto de su arquitectura" o la que, unos años antes, concretamente en 1774, también pronunció el inglés William Dalrymple al indicar que el claustro constituía "un trozo de arquitectura hermosa y elegante, del orden dórico" ${ }^{\prime \prime}$, lo que no deja de resultar tremendamente elogioso teniendo en cuenta que el militar británico apenas menciona ninguna otra construcción de las existentes en la ciudad de Santiago.

Sea como fuere, todas estas opiniones, a su manera, fueron precursoras de la que tiempo después, creo que con cierto tono admirativo, le dedicó el alemán Otto Schubert al decir que "esta arquitectura de grandes trazos $y$ sin adornos, animada por vigorosas sombras" prestaba al patio un sello de "solemne severidad", lo cual es indudablemente cierto y una descripción casi perfecta de lo que, en efecto, el claustro produce en el especta-

\footnotetext{
${ }^{2}$ MURGUÍA, 554.

${ }^{3}$ KUBLER, 346. En concreto lo atribuye al arquitecto Fernando de Casas.

${ }^{4}$ LABORDE, 329. También puede consultarse al respecto GARRIDO, 230.

${ }^{5}$ Cit. por MERCADAL, III, 693. Más información en GARRIDO, 210-216.

${ }^{6}$ SCHUBERT, 228.
} 
dor. Fue, pues, Schubert el que quizás expresó mejor la realidad arquitectónica del patio benedictino y el que preparó el terreno para juicios posteriores más positivos. De ahí que no deba sorprender que Bonet Correa, ya en la década de 1950, lo considere obra "grandiosa"y monumental y todo un modelo tanto para la arquitectura gallega de su tiempo, como para el famoso claustro de la Clerecía de Salamanca ${ }^{7}$ que es obra del arquitecto gallego Andrés García de Quiñones y que pasa por ser, de nuevo en palabras de Schubert, "una de las creaciones más acabadas de todos los paises" ${ }^{18}$.

Una obra tan notoria como la del claustro compostelano, en todo caso, nunca hasta hoy ha dejado de resultar polémica y conflictiva para muchos de los autores que la han abordado, tal vez por las muchas dudas que desde siempre ha planteado la cronología de su construcción y asimismo todo lo referente al autor de sus trazas. Quizás en ello haya influido el que su fábrica se dilatase a lo largo de más de un siglo y que por esta razón fuera necesario que trabajasen en él muy diferentes artífices; casi la práctica totalidad de los distintos maestros de obras que prestaron sus servicios en ese tiempo en la poderosa Abadía de San Martín. Por consiguiente, lo que pretendemos aquí es aclarar en lo posible todo este conflicto que pasa por atribuir las más de las veces la fábrica al siglo XVII y sus trazas al arquitecto granadino Bartolomé Fernández Lechuga, aunque haya habido voces que prefieran atribuirlo a otros autores distintos y más tardíos como es el caso de Peña de Toro, Melchor de Velasco, Fray Gabriel de Casas o el propio Fernando de Casas.

Bien es verdad, como ya se ha dicho, que no se puede negar que muchos de ellos tuvieron que poner sus manos necesariamente en el patio compostelano por ser su proceso constructivo excesivamente largo; pero debe decirse que la gran mayoría, si no todos menos el que lo trazó, no pasaron de actuar en este terreno como meros constructores $y$, por tanto, como fieles intérpretes de un plano original que es el que le otorga su enorme unidad estilística. Y de hecho basta echarle tan sólo una rápida mirada para comprobar que, en efecto, el claustro de Pinario no puede más que responder a un plan estricto y preciso, perfectamente unitario y

\footnotetext{
${ }^{7}$ BONET, 157.

${ }^{8}$ SCHUBERT, 211.
}

"CUADERNOS DE ESTUDIOS GALLEGOS", Tomo XLI, Fascículo 106, Santiago 1993-94. 
grandioso además, que tanto es fiel al espíritu como a la letra de una determinada tendencia arquitectónica del siglo en que se trazó; eso sí, con la sola excepción de los pináculos barrocos que lo rematan en su silueta general y que son, ciertamente, aditamentos posteriores que rompen en parte con su clasicismo y reciedumbre.

\section{EL CLAUSTRO. LOCALIZACIÓN Y ORGANIZACIÓN AR- QUITECTÓNICA}

A buen seguro, junto a la iglesia monacal y la fachada monástica que abre grandiosa su Puerta Real a la actual plaza de la Inmaculada, el Claustro de las Procesiones no hay duda que se constituye en la obra más pública y monumental de todo el complejo benedictino. No es casual, por tanto, que se lo diseñara justamente como un elemento puente entre estas dos zonas representativas y, por ello, sirviendo a la vez de gran elemento de contención del cierre sur del templo allí donde más lo necesita - la zona del crucero y del esbelto cimborrio-y de zona de desembarco tras el vestíbulo que se abre tras la puerta principal (Figs. 2 y 3). Es, pues, un ámbito interior de signo claramente representativo, lo que explica, entre otras cosas, que se configurase con unas dimensiones y unas formas arquitectónicas verdaderamente magníficas y suntuosas a tono con la dignidad y poder económico que entonces poseía la Abadía benedictina.

Debe recordarse que, en torno a él, se organizaban todas las procesiones monacales antes de acceder, solemnes y ordenadas, al interior de la iglesia; que también por él, viajeros y peregrinos - recuérdese que con frecuencia fue San Martín alojamiento de nobles y príncipes durante su estancia en Compostela, como fue el caso del pretendiente al trono inglés Jacobo Estuardo que visitó la ciudad en 1719- accedían a la gran hospedería que había en su interior; añádase finalmente que en su entorno estaban distribuidas las dependencias monásticas de carácter más público y exterior como pudieran ser la portería y el zaguán, las bodegas en las que estaba la sala en donde se repartían las limosnas a los pobres; y junto a ello también estaban allí la mayordomía y la botica, las escaleras de cámara y la cámara del Abad, así como la cárcel seglar y sala de la audiencia y, especialmente, la gran biblioteca que daba fama al Monasterio y cuya 


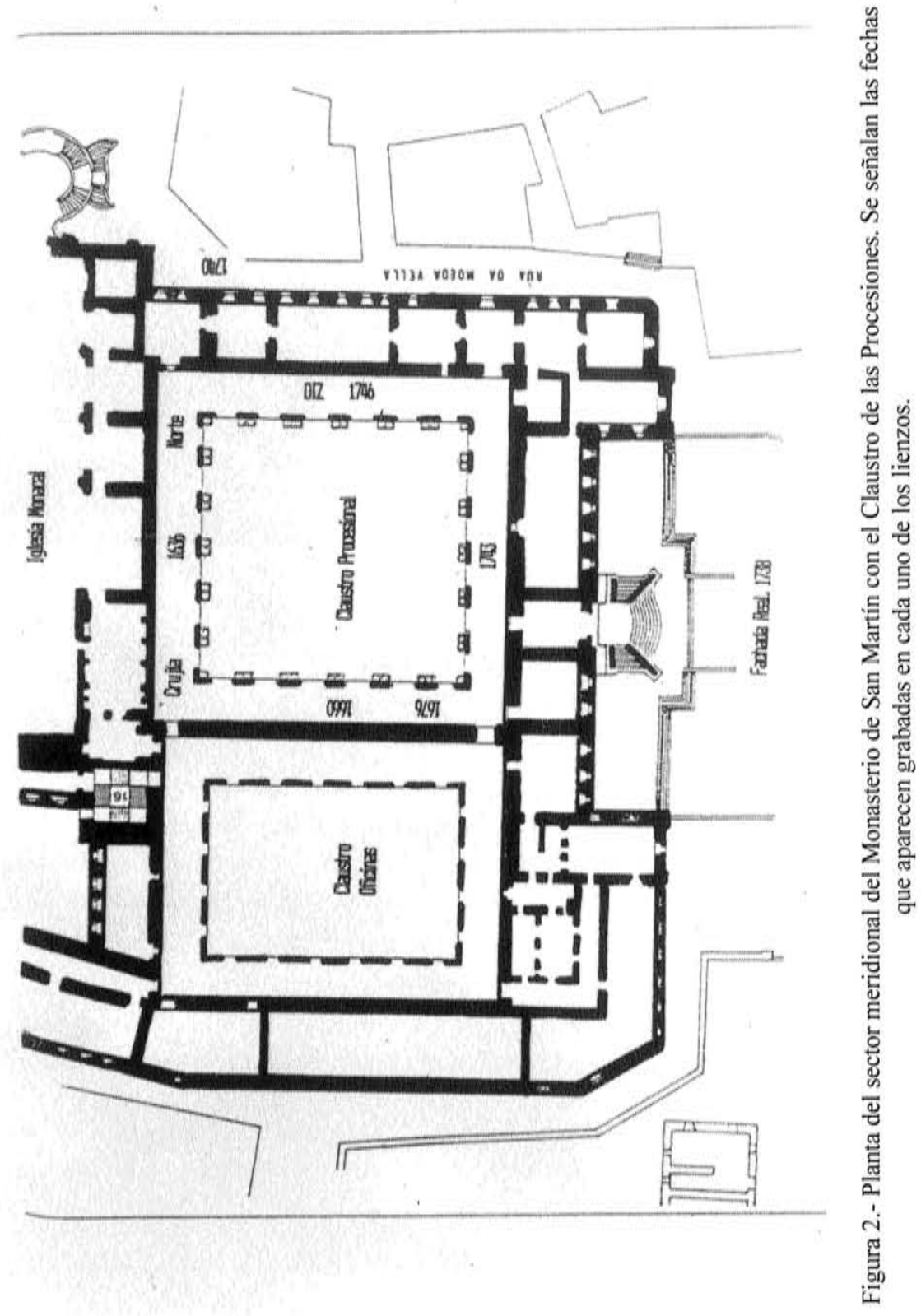

(c) Consejo Superior de Investigaciones Científicas Licencia Creative Commons 3.0 España (by-nc) 


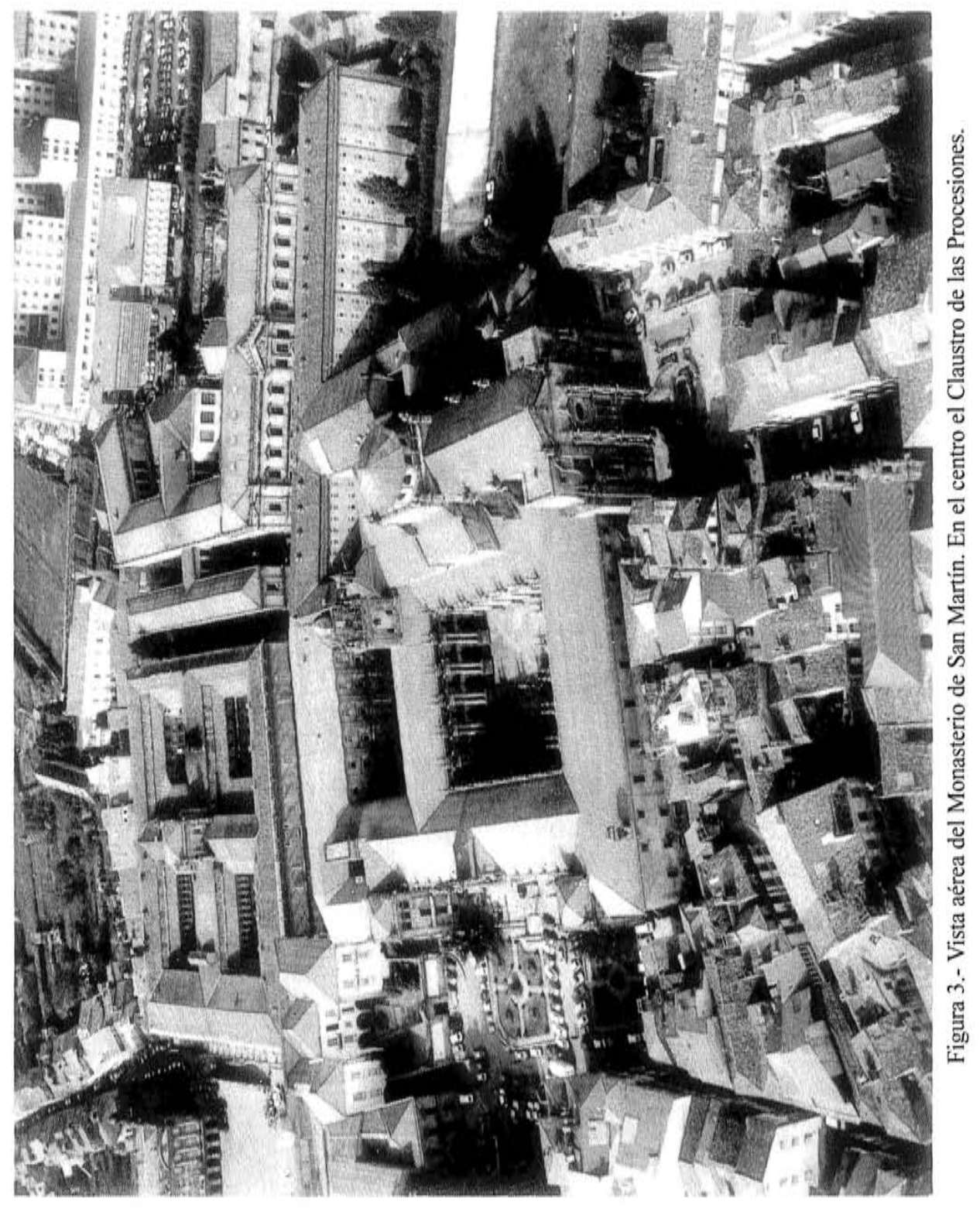


estantería barroca hoy guarda la Universidad compostelana ${ }^{9}$. Es fácil entender, por lo tanto, que con unos usos tan públicos y cualificados se le otorgase a este claustro el rango de principal, sobre todo comparado con el más reservado e íntimo de las Oficinas que poseía un tono más recogido y discreto, acaso por estar destinado a servir de centro de distribución de las zonas más específicamente domésticas como pudieran ser las cocinas y el refectorio, la sala capitular o toda la vasta zona destinada a celdas y dormitorios de la mayor parte de la congregación.

Ya hemos dicho que debido a su carácter de claustro principal, desde el principio fue configurado con una grandeza arquitectónica muy especial que, quizás en su escala, quiso emular el tono monumental del patio catedralicio diseñado por Juan de Álava en el siglo anterior. Es, pues, más que posible que el ámbito capitular de la Catedral compostelana sirviese de imprescindible referencia a la hora de dar la medida magnífica que tiene el de San Martín. Sin embargo, en el resto de sus peculiaridades, es innegable que el gran claustro benedictino responde a otras características distintas que nada tienen que ver con las que rigen el patio catedralicio.

Básicamente viene a configurar un recinto de planta rigurosamente cuadrada recorrido de severas galerías de muros lisos, pilares de sección rectangular montados sobre un basamento corrido, y todo cubierto por unas sólidas bóvedas de arista que se ven atravesadas en sus tramos por unos fortalecidos arcos de sección semicircular ${ }^{10}$. Todo es reciedumbre y austeridad, como si el diseño quisiese resaltar tan sólo la potencia del material granítico en el que está construido y la calidad estereotómica del corte de la piedra que lo conforma. Por lo demás, apenas hace concesiones al ornato, con la única excepción de las molduras que recorren los ángulos de las formas arquitectónicas, las cornisas que rematan los pilares y el discreto

\footnotetext{
${ }^{9} \mathrm{El}$ uso de las dependencias que se disponen a su alrededor aparece mencionado en los planos que, referidos al claustro, fueron ejecutados en 1727 y hoy se conservan en el Archivo Histórico Nacional. Vid. BONET, lám. 254, 255 y 256. También, aunque con la fecha confundida ya que se datan en 1707, aparecen reproducidos en SCARLATTI, 304. Finalmente vid. FERNANDEZ REY, 365 y ss. Respecto a la Biblioteca debe recordarse que fue alabada por LABORDE, 329 y comenzada a formar al parecer en el siglo XVI. Vid. MORALES, 131. Este autor que escribe en 1572 refiriéndose a ella dice textualmente: "San Martín... no tiene reliquias notables, ni libros antiguos, sino una Librería que va haciendo el Abad que agora es, muy rica de lo impreso".

${ }^{10}$ Conforma al parecer un cuadrado de 46,5 metros de lado y sus galerías laterales tienen una anchura de 5,59 metros. Vid. SCHUBERT, 227.
}

"CUADERNOS DE ESTUDIOS GALLEGOS", Tomo XLI, Fascículo 106, Santiago 1993-94. 


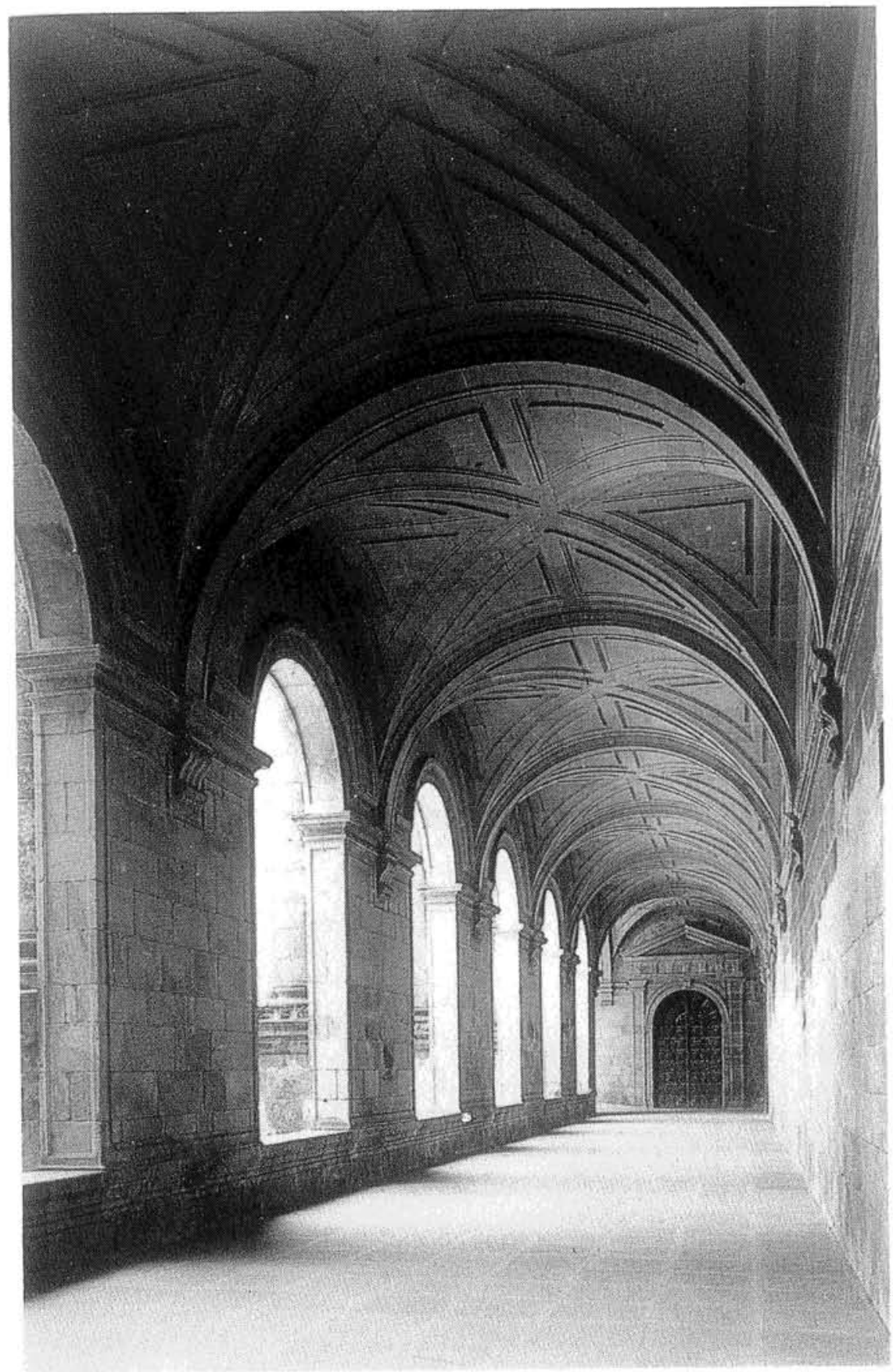

Figura 4.- Galería interior del Claustro Procesional. 
juego abstracto y geométrico que cualifica todo su abovedamiento interno que, a su vez, sirve de sostén a la galería alta (Fig. 4). Se ve, pues, que el espíritu del clasicismo seiscentista anima aún sus formas y diseño, tal y como se ve en las discretas ménsulas que sirven de arranque a los arcos de medio punto que surcan las bóvedas, y en las muy sobrias portadas de orden dórico con frontón triangular que se abren, con finalidad funcional y perspectiva a la vez, en cada uno de los ángulos en que se cruzan las diferentes crujías.

Al mismo tiempo, los seis arcos que configuran sus pandas se abren al patio interior sobremontados ya en esta zona por una recia estructura mural presidida por volados balcones, amplios vanos rectangulares flanqueados de pilastras y remates de bolas de tipo herreriano y un tragaluz elipsoidal, todo rematado por una potente cornisa que define su recorrido alto. Por tanto, aquí, en las pandas abiertas al patio, también dominan los criterios arquitectónicos adustos y recios. Aun así, nada hasta aquí llamaría la atención de no ser por la estructura de refuerzo y ornamental que confiere al patio su talante singular y verdaderamente magnífico. Me refiero, como es lógico, a la poderosa articulación de columnas dóricas geminadas que, montadas sobre altos plintos y rematadas en un plástico fragmento de entablamento, estructuran verticalmente la totalidad de los lienzos salvo en las esquinas en donde la disposición geminada adopta una forma singular de una columna única. No es más, por consiguiente, que una estructura adosada; una forma que trata de articular, ennobleciendo a la vez, las pandas del gran claustro; pero no hay duda que, tan sólo con ello, el patio procesional benedictino alcanza así una potencia plástica y una gravedad tan contundentes que yo diría no tiene parangón con nada de lo que hasta entonces se había construido.

Visto así, podría afirmarse que, como pocos, su autor no sólo utilizó como nadie el material pétreo de la región, los estrictos cortes de piedra de un habilísimo cantero y los discretos y suaves juegos geométricos de un tardoclasicismo bien aprendido, sino que también dramatizó el conjunto con un sabio y poderoso juego de columnas gigantes que otorgan al conjunto un carácter casi sobrecogedor a la par que enormemente retórico. Pocas obras, por su grandeza, expresan pues mejor la idea de seriedad tectónica y de poder monacal; hasta el punto que tanto las proporciones, como la escala y aún su propia densidad material hablan a las claras de una arquitectura abrumadora y sorprendente que, en efecto, impacta con certeza sobre todos los visitantes.

Ahora bien, tal y como ya se ha comentado, hoy el claustro remata en

"CUADERNOS DE ESTUDIOS GALLEGOS", Tomo XLI, Fascículo 106, Santiago 1993-94. 
su parte alta con una cuidada serie de pináculos barrocos semejantes a muchos de los que animan otras construcciones de la ciudad de Santiago. Es evidente que son un añadido posterior ${ }^{11}$. Sin embargo, aunque no existan pruebas de ningún tipo que lo confirmen, es más que probable que el proyecto originario tuviese otra culminación muy diferente; quizás una balaustrada convencional jalonada de pedestales y bolas, en línea con la que, también con enorme contundencia postherreriana, culmina la estructura portante del cimborrio de la iglesia y hasta los propios contrafuertes que sostienen la alta fábrica de la nave mayor.

En todo caso, fuese o no así, lo que no deja de llamar la atención es el cambio de lenguajes que, a partir de entonces, se experimenta en la arquitectura del gran Monasterio; desde las ligeras aunque altas estructuras de la iglesia que se empieza a construir. a finales del siglo XVI, hasta las pesantes y adornadas formas ya barrocas que proliferaron en la segunda mitad del siglo XVII en la fábrica de la Abadía. En este sentido, las formas severas y recias que dominan el patio bien pudieran verse como una innovadora y decisiva transición que, por cierto, dejó su eco evidente en la Fachada Real así llamada tanto por su carácter representativo y público como por el escudo del Rey que preside su remate.

\section{CRONOLOGÍA Y PROCESO CONSTRUCTIVO}

Como resultado de las obras que, desde 1627, se estaban llevando a cabo en el crucero y cimborrio de la iglesia, no hay duda que fue necesario erigir con urgencia parte del Claustro de las Procesiones al menos en el frente que miraba al norte que es, precisamente, el que se encuentra adosado a esta parte tan necesaria del gran complejo eclesiástico (Fig. 5). Piénsese al respecto que, como en su día señaló Barreiro, fue durante el segundo mandato del abad Diego de Hevia, que se desarrolló entre 1633 y 1637, cuando, para fortalecer la estructura del cimborrio, fue preciso hacer unos contrafuertes y una pared de contención que, según él, se reforzó todavía más con la construcción de "la primera parte del claustro"12. Ni que decir tiene que esta opinión está llena de sentido. Sin embargo, aunque la afirmación de Barreiro en buena parte es cierta, debe decirse que no responde

\footnotetext{
"Parecen, en efecto, obra de la segunda mitad del siglo XVII.

${ }^{12}$ BARREIRO, 157.
}

"CUADERNOS DE ESTUDIOS GALLEGOS", Tomo XLI, Fascículo 106, Santiago 1993-94. 


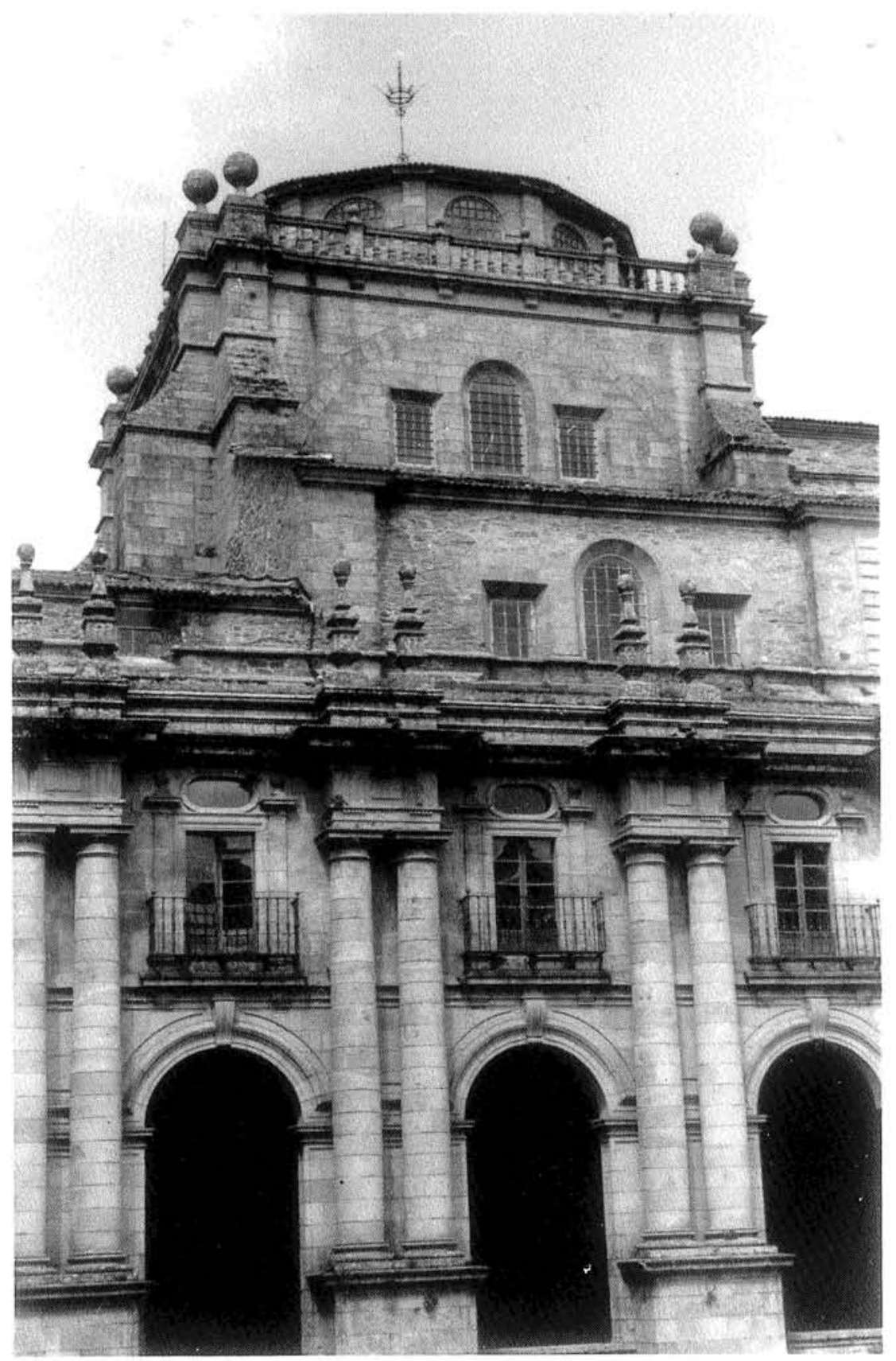

Figura 5.- Vista del lienzo norte adosado a la Iglesia. 
del todo a la verdad, ya que por otros documentos sacados a la luz hace tiempo por Pérez Costanti, consta con claridad que en 1633 el claustro en cuestión ya estaba en obras pues se manda al arquitecto "asistir por su persona y ejecutar la traza del claustro nuevo y demás obras y reparos que se ofreciesen en la nueva iglesia y claustro que se hace en dicho monasterio"13.

Pues bien, siempre se ha interpretado que el "claustro nuevo" que se pide se trace, no podía ser otro que el Procesional ${ }^{14}$ y el "que se hace", por el contrario, el contiguo de las Oficinas ${ }^{15}$ que, según Bonet, fue el primero que se levantó en el gran complejo de la Abadía ${ }^{16}$. Pero desde mi punto de vista creo que la lógica constructiva así como los propios hechos exigen, justamente, que el proceso fuese al revés. Es decir, que primero debió erigirse la parte del claustro grande que era necesaria para la consolidación de la iglesia cual era el paño norte, y que luego debió acometerse la construcción del patio "nuevo" llamado de las Oficinas que era, en este sentido, más prescindible, una obra menos urgente y que asimismo tenía una localización más interior. Y que las cosas fueron así parecen desprenderse al tener constatación de que el claustro doméstico se empezó mucho después; en concreto a partir del mandato del abad Benito Moxica que rigió los destinos del Monasterio desde 1665 hasta $1669^{17}$.

Así las cosas, nada hay que impida asegurar que el Claustro de las Procesiones, ya en obras en 1633, debió trazarse entre 1627 y 1632 y, quién sabe, hasta es posible que su fábrica se iniciase de inmediato a la par que se culminaba el remate exterior del crucero y cimborrio del templo benedictino $^{18}$. De ahí que ya estuviese en obras en el año señalado y que,

${ }^{13}$ PÉREZ COSTANTI, 188-189.

${ }^{14}$ MURGUÍA, 554; PÉREZ COSTANTI, 189, nota 1; BARREIRO, 156; PITA, 555 y SA, 53

15"Claustro viejo" lo llama MURGUÍA, 554. Esta es también la opinión de ORTEGA, 307.

${ }^{16}$ BONET, 153.

${ }_{17}$ Vid. en efecto BARREIRO, 162. En todo caso, estos datos referidos al claustro doméstico sólo explicarían la ejecución del cuerpo bajo ya que, como es sabido, el piso superior todavía tardó algunos años en ser acometido según señala una inscripción grabada en el entablamento de su cierre sur que da la fecha de 1677. Cfr. VILA (1993, I), 293.

${ }^{18}$ De hecho, se estaba trabajando en él en 1630, todavía continuaban las obras en 1636 y no es hasta 1644 cuando el abad toma la determinación de retejar la Cúpula "para que no se pierda obra tan majestuosa y de tanta importancia". Vid. respecto a ello PÉREZ COSTANTI, 364-365, nota 2 y BARREIRO, 158. Sobre la obra del cimborrio en particular creo que es útil, además de la obra ya referida de BONET, 153-156, la revisión hecha recientemente por VIGO, 352-353.

"CUADERNOS DE ESTUDIOS GALLEGOS", Tomo XLI, Fascículo 106, Santiago 1993-94. 
sólo tres años después, en 1636, conste el cierre Norte como enteramente culminado tal y como confirma un documento que de nuevo sacó a la luz Pérez Costanti -"que en estando acabado el paño del claustro que oy se va haciendo..."19- y asimismo la fecha 1636 que aparece grabada, con absoluta claridad, en la metopa que sobremonta el par de columnas dóricas del centro ${ }^{20}$.

No voy a negar que, respecto a esta data, en alguna ocasión se ha dicho que no se lee bien y que allí donde pone 1636 otros ven otra muy distinta que retrasaría la obra, nada menos que veinte años; es decir hasta $1656^{21}$. Sin embargo, sobre este aspecto, hay que señalar que el error que se comete en la segunda lectura es manifiesto, ya que se ve perfectamente la fecha que hemos dado en primer lugar y además es indudable que por su ubicación se refiere a una data de remate de todo este sector del claustro grande. Por tanto, conviene que retengamos las fechas dadas como seguras ya que a la postre resultarán determinantes a la hora de atribuir las trazas a un determinado autor.

Con todo, por más que las obras del claustro se iniciasen en fecha tan temprana y se concluyese el cierre norte hacia 1636 , concentrados como estaban los frailes en rematar de una vez las interminables obras del tem$\mathrm{plo}^{22}$, parece que, por unos años, abandonaron la fábrica del patio al menos hasta el segundo mandato del abad Miguel de Luján que tuvo lugar entre 1657 y $1661^{23}$. No obstante, en estas fechas que acabamos de mencionar consta, en efecto, que comenzó una segunda campaña constructiva que, esta vez, se concentró en el lienzo Oeste de Poniente, acaso porque en esta ocasión había el interés de acometer precisamente aquella zona del claustro y monasterio que, a posteriori, permitiría también la ejecución del claustro doméstico, es decir el "nuevo" de las Oficinas que justamente estaba previsto levantar detrás ${ }^{24}$.

${ }^{19}$ PÉREZ COSTANTI, 365, nota 2.

${ }^{20} \mathrm{La}$ lectura de la fecha, en efecto, no ofrece duda alguna. También la han leído así MURGUÍA, 554 y VILA, 75 entre otros.

${ }^{21}$ Esta es, al menos, la fecha que propone sin fundamento ORTEGA, 307 y por la que también parece inclinarse MARIAS, 179.

${ }_{22} \mathrm{Al}$ parecer fue culminada en 1645 y consagrada tres años después, en 1648. Cfr. MURGUIA, 551 y SA, 29.

${ }^{23}$ BARREIRO, 161.

${ }^{24}$ No obstante, aunque las obras en el Claustro de las Oficinas empezaron por entonces, en modo alguno invalidan que éste responda en casi todo lo fundamental al proyecto de "claustro nuevo" que menciona el documento de 1633 ya señalado. Por tanto, estoy con BONET, 153, en que el claustro debe atribuirse a Bartolomé Fernández Lechuga, por más

"CUADERNOS DE ESTUDIOS GALLEGOS", Tomo XLI, Fascículo 106, Santiago 1993-94. 
Una vez más la prueba documental referida a este sector del patio se confirma con la fecha 1660 grabada en la metopa del centro. Por tanto, a tenor de los años en que en esta parte se trabajó es más que posible, como alguna vez se ha señalado, que la ejecución de esta panda se debiera al maestro salmantino de San Martín, José de la Peña de Toro ${ }^{25}$, lo que no excluye que, en todo lo fundamental del patio: formas, estructuras, columnas y monumentalidad, respetase cuidadosamente el diseño originario establecido, como ya se ha dicho, algunas décadas antes. En esta zona del patio, no obstante, justo en la metopa del par de columnas que más se aproxima a la unión con la panda Sur aparece grabada otra fecha que, sin problemas interpretativos, pone 1676. Quiere esto decir que esta zona del rincón claustral debió acometerse después, más o menos coincidiendo con las obras que, también entonces, se estaban llevando a cabo en el cuerpo alto del Claustro de las Oficinas. Conviene recordar que esta parte del patio interior se construyó durante el abadiazgo de Fray Luis de Bustamante que se desarrolló de 1673 a $1677^{26}$. Así pues, tiene sentido que ambas obras coincidan en el tiempo ya que el muro de cierre de esta crujía central actúa como medianero entre los dos patios que presiden el Monasterio. Dada la fecha, sobra indicar que esta zona concreta del claustro grande, así como el cuerpo superior del patio de las Oficinas, es muy probable que fuesen levantadas por un tercer maestro de obras vinculado por entonces a San Martín como era el caso de Fray Tomás Alonso que, por lo demás, a diferencia de Peña de Toro, pertenecía a la Orden Benedictina y era además monje perteneciente a la propia congregación ${ }^{27}$.

Ahora bien, a partir de esta data parece que, de nuevo, las fechas constructivas referidas al claustro principal vuelven a posponerse y a dilatarse en el tiempo hasta bien entrado el siglo XVIII. Tal vez se expliquen porque, durante este lapso de tiempo, el afán constructivo de Pinario, primero tuvo que demorarse por motivo de un conflicto que las obras de la Abadía generaron con la Catedral y que no se resolvió hasta 1693 en que tuvo

que VILA (1993, I), 293 y (1994), 453 y 456 nota 10, prefiera adscribir el cuerpo bajo a José de la Peña de Toro "o incluso a Melchor de Velasco" y el superior a Fray Tomás Alonso. Seguramente estos arquitectos se limitaron a dirigir la construcción respetando el diseño primitivo, aunque es probable que introdujesen tímidas reformas en el sistema de vanos que se ven en él.

${ }^{25}$ Vid. VILA (1993, I), 290 y 293.

${ }^{26}$ BARREIRO, 164. Vid. asimismo la nota 17 arriba cit.

${ }^{27}$ Cfr. VILA (1994), 453.

"CUADERNOS DE ESTUDIOS GALLEGOS", Tomo XLI, Fascículo 106, Santiago 1993-94. 
lugar la concordia definitiva entre ambas instituciones ${ }^{28} ; \mathrm{y}$, después, porque las obras monacales se centraron, ya con la intervención de otro monje arquitecto - Fray Gabriel de Casas-, en la construcción de parte de la Fachada Real que se abre a la plaza de la Inmaculada próxima a Azabacherías. En todo caso, no es hasta 1727 cuando, de nuevo, se vuelve a pensar en la culminación de la estructura del patio, lo que explica que fuese entonces cuando se realizan los planos que, referidos a él, se guardan hoy en el Archivo Histórico Nacional y que, en efecto, llevan precisamente esa data ${ }^{29}$.

Los dibujos mencionados referidos en particular al patio son en concreto tres. Y en el primero de ellos la leyenda que lleva manuscrita señala, efectivamente, que lo que por esas fechas restaba por hacer en el Claustro Reglar era "el lienzo de la calle (da Moeda Vella) y lienzo de la Puerta Real"; es decir los lienzos y crujías que se abren precisamente hacia el Sur y hacia la zona de Naciente. Puede afirmarse que nada apenas se había hecho por estas zonas con la única excepción del primer tramo que une la zona norte con la del este; pero todo lo demás no hay duda que tuvo que acometerse en los años posteriores.

Una vez más, por Barreiro sabemos que el nuevo impulso se demoró hasta el mandato del abad José Cornejo establecido entre 1733 y $1737^{30}$, aunque no conocemos, si entonces las obras fueron a buen ritmo. Tuvieron, no obstante, que simultanearse con las de continuación de la fachada principal y, posteriormente - ya con los abades Augusto de Taboada (17371741), Manuel de las Heras (1741-1745) y Pedro de Mesa (1745-1747) con las del cierre monástico que da a la calle da Moeda Vella. Sea como fuere, estas realizaciones son las que explican que las obras en la fachada principal se culminasen en 1738 con la instalación del remate alto que lleva el Escudo Real ${ }^{31}$ y, en la crujía del claustro, con todo el lienzo del Sur que está justamente detrás y que por ello lleva la data de 1743 en el lugar acostumbrado. No con ello remataban las obras del gran patio benedictino; faltaba todavía por hacer la casi totalidad del cierre Este y parte también del muro externo que da a la calle lateral ya mencionada. Precisamente, en esta parte del cierre monástico uno de sus elementos arquitectó-

\footnotetext{
${ }^{28}$ BONET, 482.

${ }^{29}$ Son los referidos en la nota 9.

${ }^{30}$ BARREIRO, 174.

${ }^{31}$ Esta es, en efecto, la data que aparece grabada en la Portada Real del Monasterio.
} 
nicos más significativos, la llamada Puerta de los Carros, lleva la fecha de 1740. Es, pues, un nuevo dato cronológico que sirve para comprobar el avance de las obras por esta parte del edificio; y se completa finalmente con la que una vez más, en el lugar correspondiente, lleva asimismo esculpida la panda del claustro. El problema reside en que esta segunda fecha resulta más compleja en su lectura que las demás, ya que un cierto grado de deterioro puede conducirnos a error. Se ha interpretado unas veces como $1743^{32}$; otras como $1747^{33}$, aunque en mi opinión parece que debe leerse como $1746^{34}$. Por cierto que, de todas las fechas grabadas que se han mencionado, ésta del lienzo oriental es la única que, además del año, lleva también una referencia que, sin problema alguno, deja ver las letras DIZ. Parece lógico interpretarlas como abreviatura del mes de DIZiembre. Por tanto es más que factible que con esta precisión los monjes benedictinos quisieran dejar constancia no sólo del año en que la obra se remató, sino incluso del mes, lo que refuerza ciertamente la tesis de que entonces toda la obra se daba por culminada.

Por lo demás, ni que decir tiene que, dada la cronología tardía de todo este amplio sector del Monasterio y del claustro, es más que probable que fuese construida por el arquitecto que entonces estaba vinculado a las obras de San Martín. De ahí que nadie dude de la responsabilidad de Fernando de Casas $^{35}$ a pesar de que, una vez más, se limitó a mantener el plan tal y como había sido previsto en el proyecto primitivo.

\section{SOBRE EL AUTOR Y SUS REFERENCIAS ARQUITECTÓNI- CAS. FERNÁNDEZ LECHUGA Y LA SÍNTESIS TARDOCLASI- CISTA}

Como cabe suponer, a tenor de las fechas que hemos establecido para el proyecto e inicio del claustro, el maestro que se encargó de su traza y

${ }^{32}$ SCHUBERT, 226; GARCÍA IGLESIAS, 176 y VILA (1993, I), 308. Por lo demás, MURGUÍA, 554, da la fecha de 1741 mientras que BONET, 156 y ORTEGA, 347, prefieren señalar la de 1738 .

${ }^{33}$ VILA (1993, I), 289-290.

${ }^{34}$ Esto justificaría, además, que apenas concluido el claustro, al año siguiente, en 1747, el abad Fray Pedro de Mesa proponga la construcción de una fuente para presidirlo que se indica debe ser "digna de aquel y de la casa". Cfr. SA, 54. La fuente se le encargó a Fernando de Casas.

${ }^{35}$ ORTEGA, 347; SA, 54; VILA (1993, I), 290 y GARCÍA IGLESIAS, 176.

"CUADERNOS DE ESTUdiOS GALLEGOS", Tomo XLI, Fascículo 106, Santiago 1993-94. 
primera construcción no pudo ser otro que el granadino Bartolomé Fernández Lechuga a quien, no sin cierta contestación por parte de algunos autores ${ }^{36}$, habitualmente se ha venido atribuyendo ${ }^{37}$. Recuérdese que en 1626, tal vez por mediación de Ginés Martínez de Aranda ${ }^{38}$ —otro andaluz que había tenido relaciones profesionales con la Abadía benedictina ${ }^{39}$ - había sido llamado por el abad de San Martín, entonces Diego de Hevia, para trazar y dirigir obras en el Monasterio ${ }^{40}$.

Debió llegar en los meses finales de ese mismo año teniendo en cuenta que ya en Enero de 1627 consta en un contrato como maestro de obras de la Abadía, ya que se especifica que varios canteros que trabajaban para el Monasterio saquen la piedra y la tallen "conforme a las medidas y contramoldes que les diese Bartolomé Lechuga maestro de la obra" de dicha congregación ${ }^{41}$. Además, es sabido que, desde esta data y hasta 1637 en que se mantuvo en el cargo antes de regresar a Granada ${ }^{42}$, no dejó de asumir otros cargos cualificados, como el de maestro de obras de la Catedral a partir de 1634; el de fontanero de la Ciudad ese mismo año ${ }^{43} \mathrm{y}$, a su vez, que tuviese vínculos laborales con otras congregaciones e institucio-

\footnotetext{
${ }^{36}$ Tal como se ha dicho, los que quieren verlo responsabilidad de otro autor son fundamentalmente KUBLER, 346; ORTEGA, 307 y MARÍAS, 179. El primero lo atribuye a Fernando de Casas, la segunda autora prefiere vincularlo al hacer de Peña de Toro o de Melchor de Velasco y, finalmente, Marías, muy crítico con la documentación y la epigrafía, sin descartar los autores señalados por Ortega Romero cree que es más verosímil hacerlo de Fray Gabriel de Casas y obra, por tanto, de finales del siglo XVII o principios del XVIII.

${ }^{37}$ Vid. BONET, 156; PITA, 555; FOLGAR, 65; SA, 53 y VILA, 74 entre otros.

${ }^{38}$ VILA (1993, II), 131. Ciertamente, en un Informe Genealógico solicitado en 1626 por el Tribunal de la Inquisición a favor de Juan de Aranda, aparece declarando Bartolomé Fernández Lechuga. Dice ser cantero y que conoce a Juan de Aranda porque se lo presentó Ginés Martínez, maestro de las Aguas. Vid. GALERA, 3 y ss.

${ }^{39}$ Había hecho, en efecto, entre 1603 y 1606 un proyecto de reforma para la iglesia de San Martín en la que corregía las trazas dadas por Mateo López unos años antes. Más información en VIGO (1994), 332, 333 y nota 44; y VIGO, 350 y ss.

${ }^{40}$ PÉREZ COSTANTI, 188.

${ }^{41}$ PÉREZ COSTANTI, 188.

${ }^{42}$ PÉREZ COSTANTI, 1991. Su regreso a Granada tuvo lugar al año siguiente en 1638. Marchó para ocupar el cargo de Maestro Mayor del Palacio de la Alhambra para el que había sido nombrado el 31 de Diciembre de 1637 por fallecimiento de Francisco de Potes.

${ }^{43}$ PÉREZ COSTANTI, 189.
}

"CUADERNOS DE ESTUDIOS GALLEGOS", Tomo XLI, Fascículo 106, Santiago 1993-94. 
nes urbanas como fue el caso de los agustinos, franciscanos, jesuitas ${ }^{44} y$ benedictinas ${ }^{45}$ y también con la Cofradía del Rosario adscrita a Santo Domingo $^{46}$ e incluso con la propia Universidad ${ }^{47}$, lo que demuestra su tremendo protagonismo en la arquitectura compostelana de su tiempo como si fuese, a los efectos, su árbitro incontestado.

Tal vez por ello Domingo de Andrade, tiempo después, no dudó en considerarlo casi como un igual de Bramante, de Fontana, de Bernini o incluso de Miguel Angel señalando que al igual que éstos, Lechuga había sido uno de los pocos arquitectos cuyo "arte" le había servido para ennoblecerse al ser distinguido por el rey Felipe IV con el hábito de caballe$\mathrm{ro}^{48}$. También Llaguno lo considera un maestro "muy acreditado" en su profesión ${ }^{49}$. Por tanto, no deja de resultar sorprendente que sepamos tan poco de él justamente en sus años de formación andaluza previos a su llegada a Compostela.

Resulta desolador, en efecto, comprobar que, al menos hasta la fecha, nada o casi nada sabemos sobre sus primeros años discurridos en el medio andaluz. Sólo conocemos que provenía del Sur y de la ciudad de Granada; que fue allí en donde aparece mencionado por vez primera en una obra insignificante y menor ${ }^{50} ; \mathrm{y}$ que, con posterioridad a esta data, hacia 1625

${ }^{44}$ Además de PÉREZ COSTANTI, 188 y ss. sobre las obras que realizó para estas congregaciones es obligada la consulta de BONET, 150 y ss.; FOLGAR, 65-68 y FOLGAR (1993), 318 y ss. Por cierto que una de ellas, la que proyectó para los agustinos, fue elogiada por el Gran Duque de Toscana Cosme de Médicis cuando se alojó en ella durante su visita a la ciudad en 1668: "Vi sono tre o quattro fabriche assai buone, la Chiese e l'Convento di San Agostino, quella di San Domenico e la Catedrale che é l'estessa chiesa si San Yago". Vid. MEDICIS, 333.

${ }^{45}$ COLOMBAS, 139 y 140 . En concreto sabemos que realizó trazas para el "Cuarto de la Quintana" del Monasterio de San Pelayo y que sobre ellas se trabajó a partir de 1641. Quiere esto decir que es muy probable que toda esta obra que habitualmente se atribuye a Mateo López sea, en realidad, responsabilidad artística de Lechuga, lo que parece más lógico teniendo en cuenta su calidad estereotómica y el trasfondo clasicista que se ve en su concepción. La ejecución, sin embargo, hay que adscribirla a Jácome Fernández, hijo, tal y como aseguran los documentos.

${ }^{46}$ Sobre ella vid. FOLGAR (1989), 251 y ss.

${ }^{47}$ PÉREZ COSTANTI, 189-190.

${ }^{48}$ ANDRADE, 31-32.

${ }^{49}$ LLAGUNO-CEAN, IV, 28.

${ }^{50}$ Consta, en efecto, que en 1619 contrató en Granada la hechura de las columnas del claustro del Convento de Ntra. Sra. de la Cabeza de carmelitas descalzas, aunque posteriormente cedió su derecho por ausentarse temporalmente de la ciudad. Vid. GÓMEZMORENO CALERA, 40 y 210.

"CUADERNOS DE ESTUDIOS GALLEGOS", Tomo XLI, Fascículo 106, Santiago 1993-94. 
había hecho una planta y alzado para levantar un tercer cuerpo con sus torres y escaleras para el Palacio de Carlos V en la Alhambra de Granada. Por lo demás, también se sabe que dicho proyecto de culminación del palacio fue juzgado en Madrid ese mismo año por hombres del prestigio de Juan Gómez de Mora y Pedro de Lizargarate y que dictaminaron que lo mejor era excusar el tercer piso y las torres, pero no así las escaleras que, según ellos, debían de ejecutarse conforme a sus trazas ${ }^{51}$. Así al menos se especifica en una Real Cédula del 6 de Enero de 1626 que al parecer también indica que, en vez del tercer cuerpo, lo mejor era rematar el edificio conforme a las órdenes dadas tiempo atrás por Felipe II, es decir con una balaustrada, sus pedestales y sus típicos remates de bolas ${ }^{52}$.

Pero más de esto nada se puede afirmar sobre sus andanzas andaluzas, lo que no impide que en su obra arquitectónica se deje entrever lo profundo de sus conocimientos en esta materia y lo mucho que el arquitecto debía a su formación en la España del Sur. En este sentido la prueba más objetiva es sin duda el propio Claustro de las Procesiones.

Respecto a ello debe señalarse, no obstante, que no hay en todo el ambiente andaluz un claustro con sus mismas características tal y como afirmó ya en su día el profesor Pita Andrade ${ }^{53}$. Ahora bien, aunque esto sea cierto desde el punto de vista tipológico, en lo que se refiere a todos y cada uno de los elementos que conforman la estructura del patio, no cabe duda que sí se aprecia una relación bastante directa con la arquitectura andaluza aunque sea a costa de sacar a colación obras de muy diverso carácter dispersas, por lo demás, por todo su amplio territorio. Así que no sólo cabe señalar su tradición andaluza, sino también su gran capacidad para interpretar de modo magnífico y muy personal los distintos lenguajes arquitectónicos que allí se daban en las primeras décadas del siglo XVII.

El lenguaje columnario, por ejemplo, que es tal vez lo más singular y característico del claustro dada su sólida y retórica grandeza, así como su uso pareado, su tono colosal y corpulento, y su manera de estar aplicado al muro sobre elevados podios y con un remate roto de entablamento, es evidente que resulta una derivación de esquemas romanos surgidos de Bramante y Rafael -Palacios Caprini (Fig. 6) y Vidoni-Caffarelli-pero conocidos ya en fechas muy tempranas en Andalucía y Granada en parti-

\footnotetext{
${ }^{51}$ LLAGUNO-CEÁN, IV, 28.

${ }^{52}$ LÓPEZ GUZMÁN, 566.

${ }^{53}$ PITA, 556.
} 


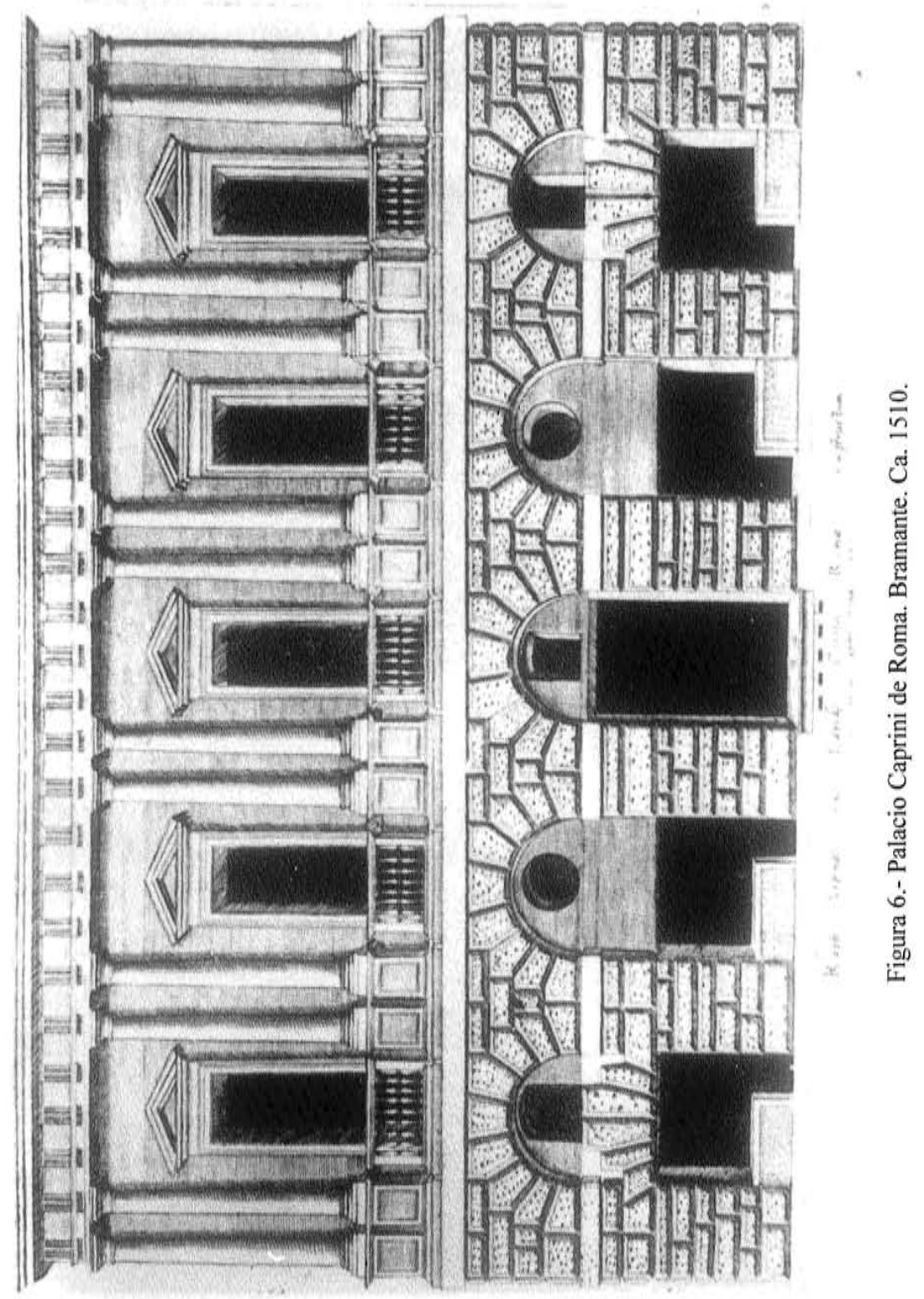


cular a través de la fachada principal del Palacio de Carlos V en la Alhambra que había diseñado Pedro Machuca hacia 1549 (Fig. 7) ${ }^{54}$. Aquí, con todo, la estructura dórica geminada, con fustes estriados, se limita a articular un sólo cuerpo, el inferior de la portada. Sin embargo, el concepto de lo colosal, también pudo conocerlo Lechuga en el ambiente arquitectónico de la Andalucía Oriental, bien a través de las corpulentas formas gigantes utilizadas por Siloé en el interior de la Catedral de Granada, o a través de Andrés de Vandelvira que también las había aplicado en la Seo jiennense $\mathrm{y}$, con una solución geminada, concretamente en esa formidable pieza que es su valiosa Sacristía (Fig. 8).

La tradición siloetesco-vandelviriana, en todo caso, no supone ninguna novedad ya que ha sido con frecuencia vinculada al hacer gallego de Lechuga $^{55}$. Por tanto, aunque indudablemente cierta, debe de completarse con otras de distinta tendencia y tradición que siempre han despertado menos atención e interés por parte de los estudiosos. Pienso, por ejemplo, que es importante para interpretar con corrección la estructura del claustro el saber que Lechuga debió conocer otras soluciones columnarias asimismo provenientes de Andalucía como pueden ser la Puerta del Puente de Córdoba, obra de Hernán Ruiz III y de 1571, o las sólidas portadas que el arquitecto Andrés de Ribera había levantado por las mismas fechas en la Cartuja de la Defensión de Jerez de la Frontera (Fig. 9) y en las Casas Consistoriales de la misma ciudad (Fig. 10). No voy a negar que en todas estas estructuras las formas adquieren un tono, aunque colosal, más ornamentado y ligero, menos serio y más dado a incorporar detalles y florituras que las hacen más vistosas y atractivas. Pero el trasfondo sí cabe considerarlo igual, aun cuando Lechuga, por tener otra formación posterior, lo matizase con otros influjos de signo más austero y rigorista.

En este sentido, fue Marías quien, sobre esta idea, subrayó que el arquitecto granadino no podía entenderse sin el influjo de Herrera, de lo herreriano y de los lenguajes postclasicistas surgidos al amparo de los Mora, Francisco y Juan ${ }^{56}$. Nada tiene de extraño, pues, que aunque Lechuga nunca hubiese salido de Andalucía hasta 1626, las formas tardoclasicistas se impregnasen en él teniendo en cuenta que pudo conocerlas en su propia tierra tanto a través de la iglesia de Santa María de la Alhambra en Grana-

\footnotetext{
${ }^{54}$ Cfr. ROSENTHAL, 92 y ss.

${ }^{55}$ Vid. BONET, 157; FOLGAR, 65 y VILA (1993, I), 289

${ }^{56}$ MARÍAS, 179.
} 
da o de la cúpula de los jesuitas en la misma ciudad, como en la Lonja de Sevilla o en las propias obras del Palacio de Carlos V que al ser construcción del Rey siempre estuvo bajo el control directo de los arquitectos vinculados a la Corona.

Tal vez por estas circunstancias, el patio compostelano es cierto que evoca en algo el tono recio y algo grave, casi sobrecogedor, que tiene el cierre principal de la iglesia escurialense en su mirar al patio de los Reyes (Fig. 11$)^{57} \mathrm{y}$, asimismo, ciertos ecos postclasicistas semejantes a los que se ven en la obra granadina de Ambrosio de Vico. Al menos eso es lo que se aprecia al comparar la estructura geminada de columnas del claustro con la portada dórica del Hospital de San Juan de Dios que este arquitecto granadino realizó en su ciudad a principios del siglo XVII (Fig. 12) ${ }^{58}$.

Por lo demás, que Lechuga conocía este tipo de estructuras de tono tardoclasicista, meridional e integrador tanto de la tradición de Herrera como de las más vistosas de la España del Sur, lo prueba su proyecto para el sepulcro del arzobispo Beltrán de Guevara sito en el interior de la Catedral de Santiago que pasa por ser obra de 1627 y de las primeras que nuestro arquitecto proyectó en la Ciudad Apostólica (Fig. 13) ${ }^{59}$.

Con todo, Lechuga no fue el único en proceder a esta síntesis arquitectónica de los dos lenguajes, pues se aprecia en otras obras andaluzas de su tiempo como es la Puerta de Córdoba en Carmona, que se levantó a partir de 1608 (Fig. 14) ${ }^{60} \mathrm{y}$, mucho después, incluso en una obra plenamente dieciochesca como era la del Palacio del Intendente en la ciudad nueva de La Carolina levantada durante el reinado de Carlos III.

Sea como fuere, además de las señaladas, son muchas las estructuras columnarias que, en Andalucía, con más o menos decoración, recuerdan la de Compostela. Yo mencionaría la solución arquitectónica dada al trascoro de la Catedral de Córdoba que se considera obra de la primera

\footnotetext{
${ }^{57}$ MARÍAS, 179.

${ }^{58}$ Sobre este arquitecto véase GÓMEZ-MORENO CALERA (1992).

${ }^{59}$ Es, ciertamente, una obra documentada de Lechuga, de 1627 y de las primeras que el arquitecto realizó a su llegada a Compostela. Vid. LÓPEZ FERREIRO, IX, 61 y 77 de los Apéndices. Su estructura, por lo demás, no hay duda que evoca el tipo de portadas frecuentes en el medio granadino como la ya señalada del Hospital de San Juan de Dios, a la que podríamos añadir la del Monasterio de San Jerónimo en Granada o la que Vico proyectó para Sta. María de la Alhambra. Vid. GÓMEZ-MORENO CALERA (1992), 108 y ss.

${ }^{60}$ Cierta Información sobre esta puerta puede encontrarse en BONET (1978), 15. Según parece se desconoce el nombre del arquitecto que la trazó.
}

"CUADERNOS DE ESTUDIOS GALLEGOS", Tomo XLI, Fascículo 106, Santiago 1993-94. 


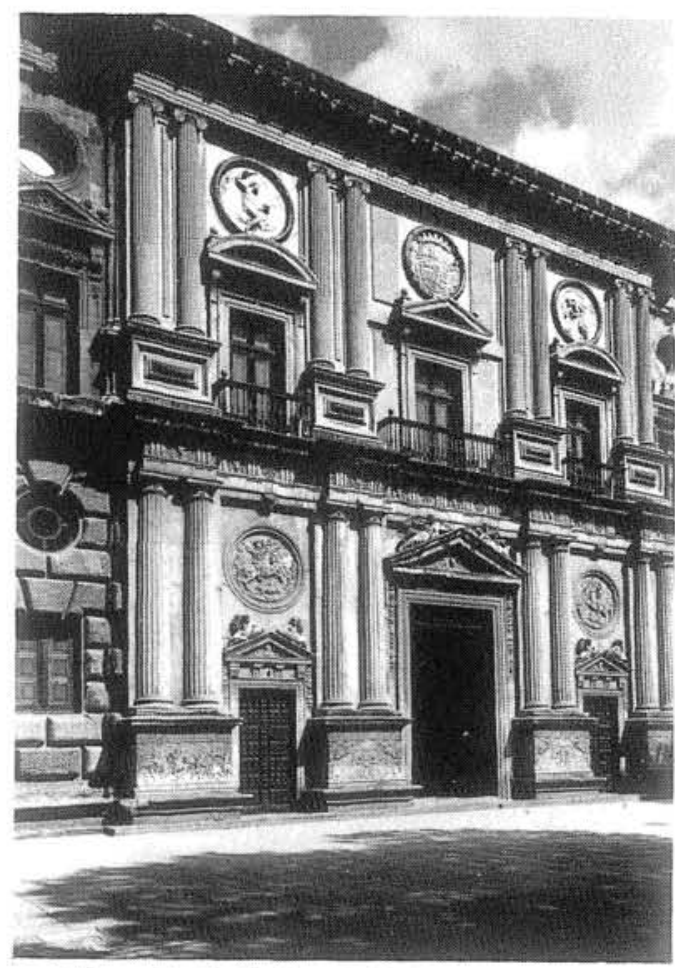

Figura 7.- Fachada principal del Palacio de Carlos V en Granada. Pedro Machuca. Ca. 1549.

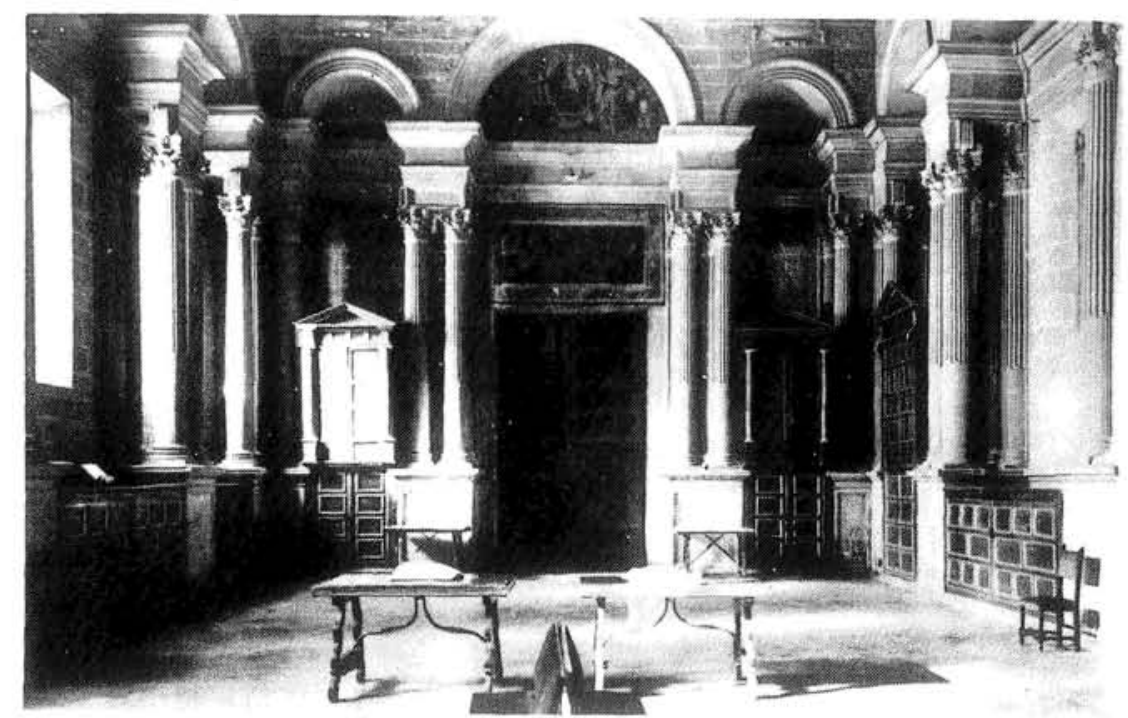

Figura 8.- Sacristía de la Catedral de Jaén. Andrés de Vandelvira. Ca. 1555. 


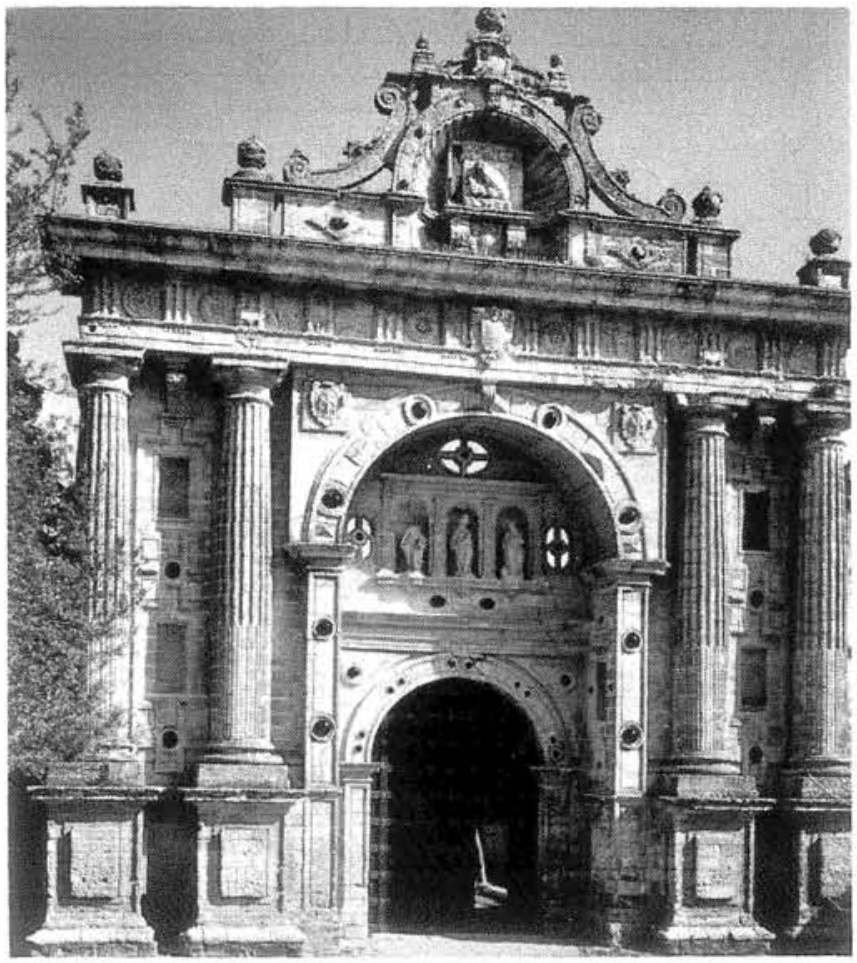

Figura 9.- Cartuja de la Defensión en Jerez. Andrés de Ribera. 1571

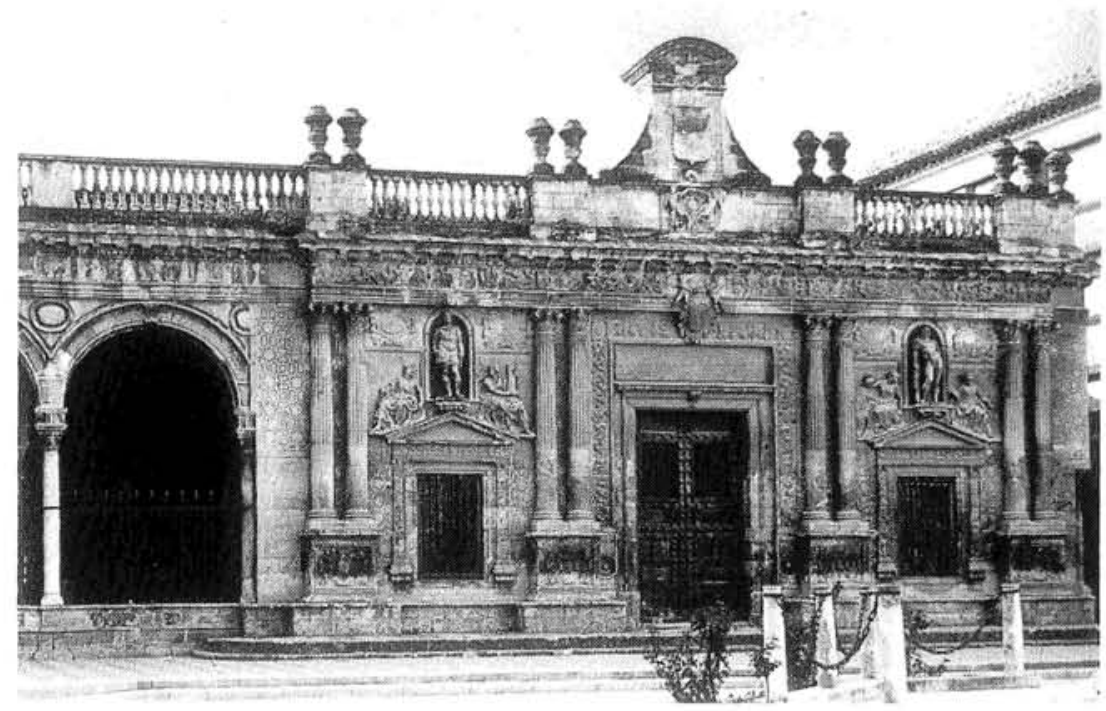

Figura 10.- Casas Consistoriales de Jerez. Andrés de Ribera. 1575. 


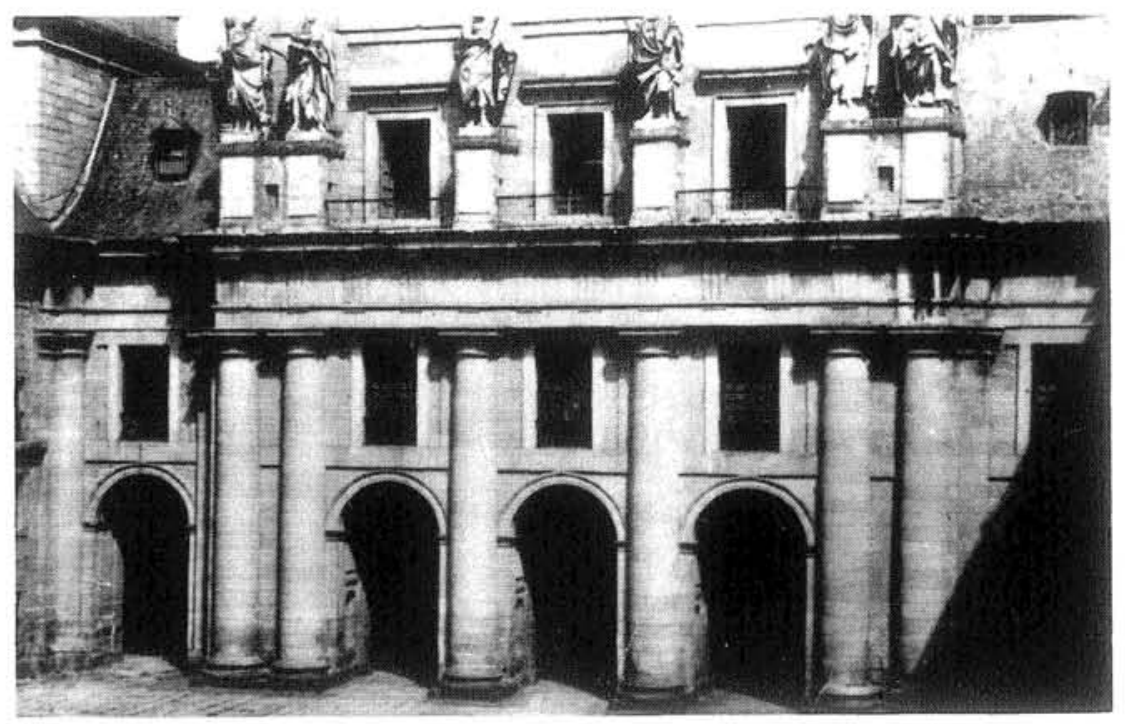

Figura 11.- Fachada de la iglesia de El Escorial. Juan de Herrera. Ca. 1575.

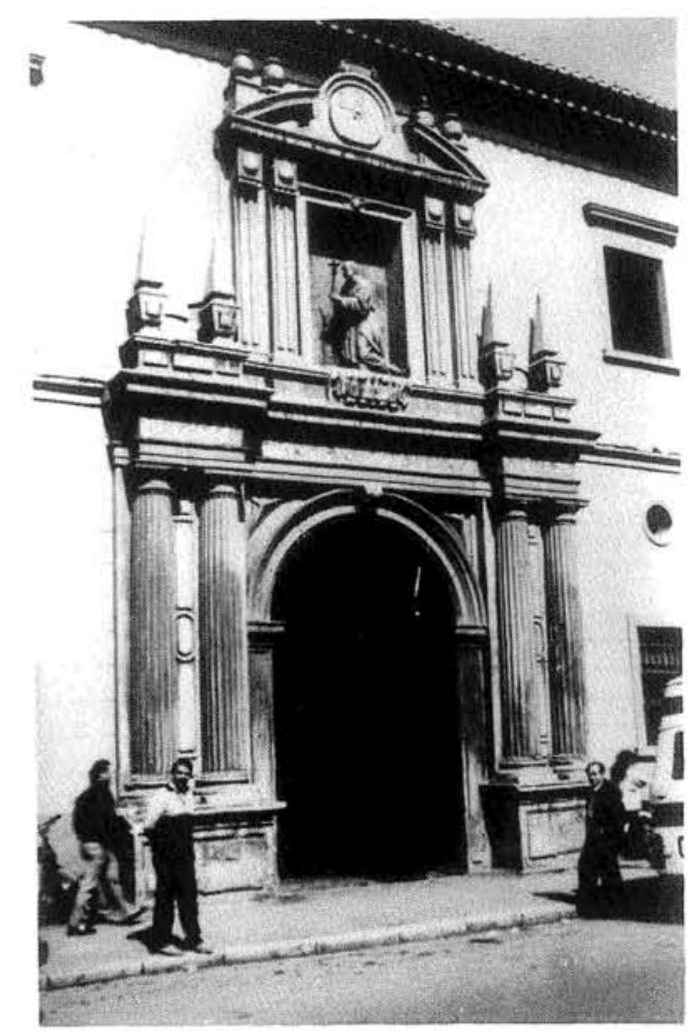

Figura 12.- Portada del Hospital de San Juan de Dios en Granada. Ambrosio de Vico. 1609. 


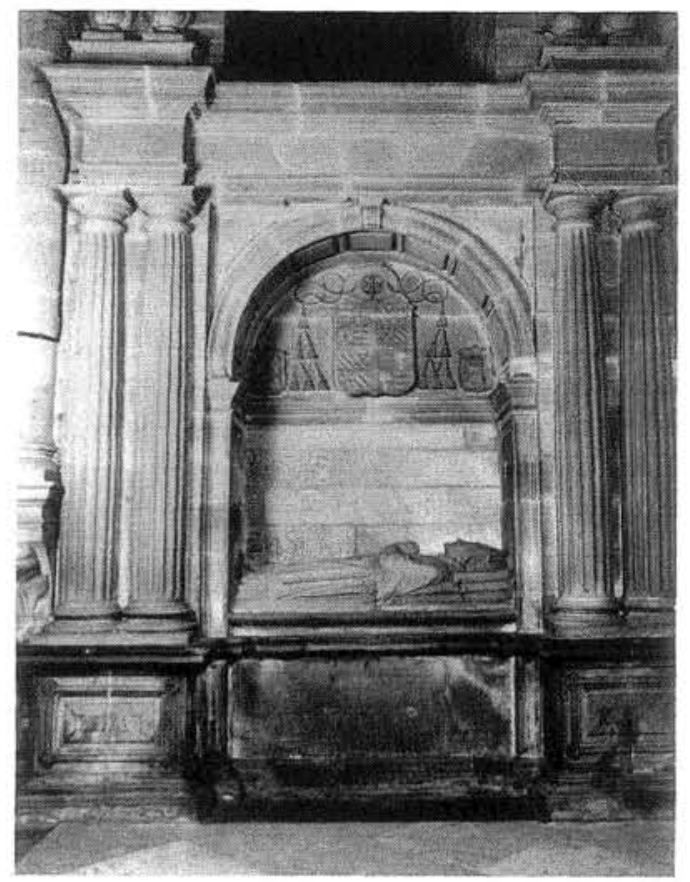

Figura 13.- Sepulcro del Arzobispo Beltrán de Guevara. Catedral de Santiago. Fernández Lechuga. 1627.

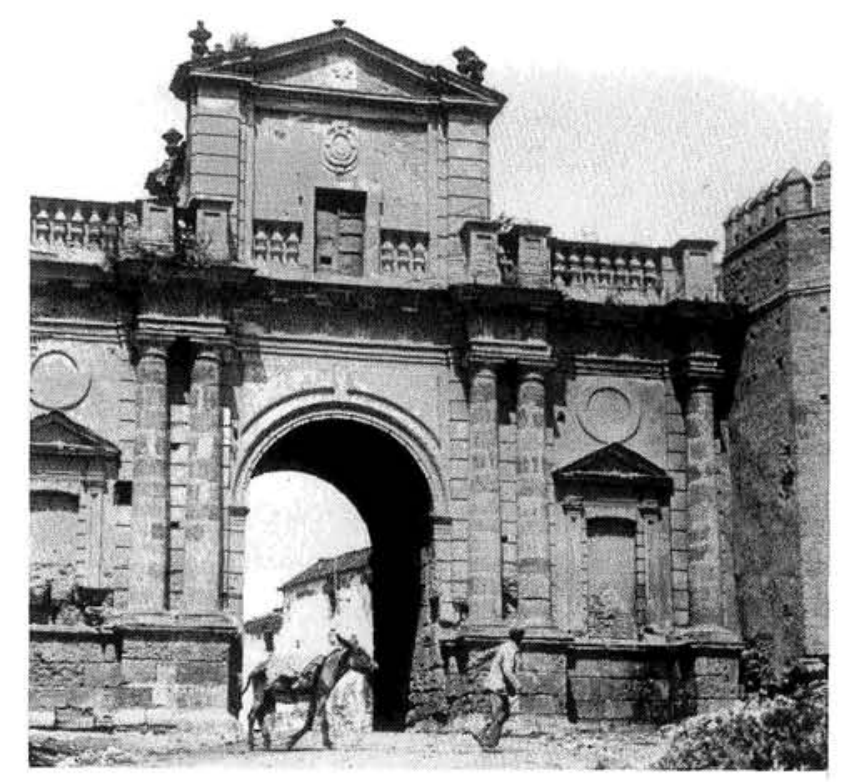

Figura 14.- Puerta de Córdoba en Carmona (Sevilla). Ca. 1608 . 
mitad del XVII y un ejemplo de arquitectura protobarroca bastante interesante (Fig. 15) ${ }^{61}$; también la propia fachada principal de la Catedral de Jaén muy vandelviriana todavía, debida a Eufrasio López Rojas y de 1667; y por último, por qué no, hasta la alta estructura inferior que, José de Bada, otro arquitecto granadino, pensó para el gran frente principal de la Catedral de Málaga aunque aquí la decoración y el aparato barroco es evidente que encaminan la arquitectura por otros derroteros ya distintos.

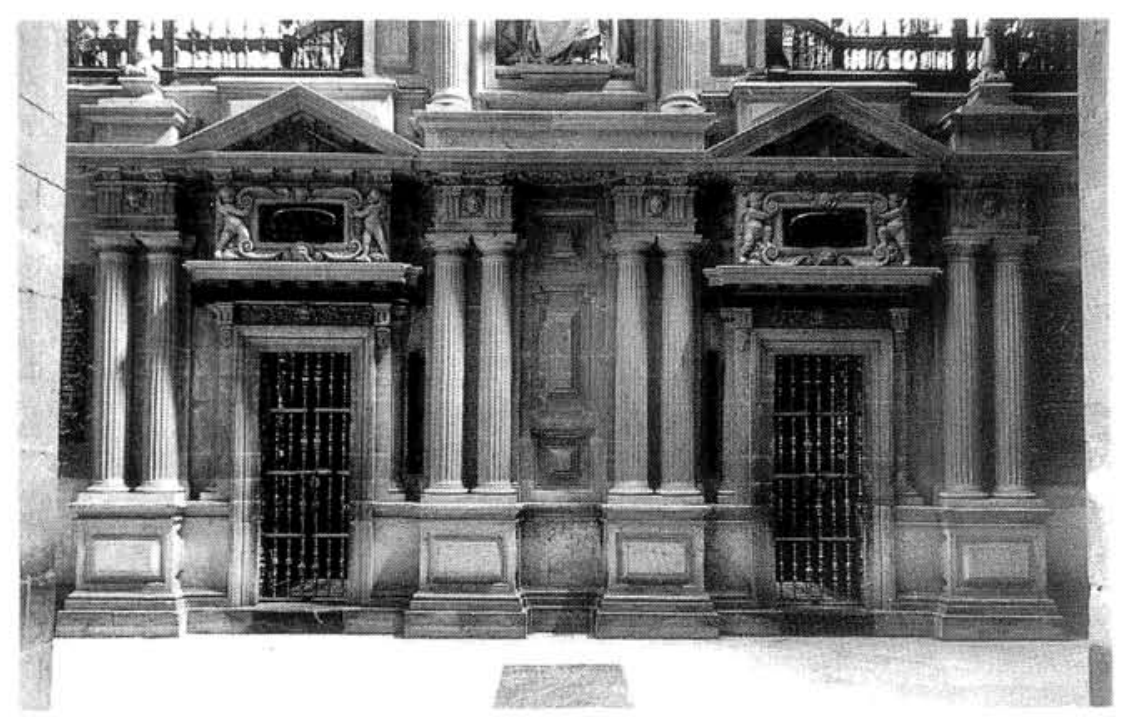

Figura 15.- Trascoro de la Catedral de Córdoba. $1^{\mathrm{a}} \mathrm{mitad}$ del siglo XVII.

Ahora bien, tanta tradición arquitectónica en absoluto empaña la calidad del claustro compostelano, entre otras cosas porque sólo aquí el diseño, las proporciones y la solidez del material expresaron como nunca la sensación de imponente gravedad tectónica. Es como si Lechuga, bien formado en el complejo y diverso medio andaluz, hubiera aprovechado las condiciones gallegas para expresar su adusto modo de hacer. De ahí que su obra fuese aquí tan apreciada - "maestro eminente" le llama el visitador real de la Universidad compostelana en $1635^{62}$ - y tuviera tan hondas consecuencias.

\footnotetext{
${ }^{61} \mathrm{Al}$ parecer no se sabe quien fue el autor del proyecto.

${ }^{62}$ Cit. por PÉREZ COSTANTI, 190.
}

"CUADERNOS DE ESTUDIOS GALLEGOS", Tomo XLI, Fascículo 106, Santiago 1993-94. 
Pero el claustro de San Martín, aun cuando llama la atención sobre todo por su plástica articulación columnaria, es algo más. Resulta interesante, de hecho, por la doble estructuración de arco-balcón que se abre en las pandas murales, así como por las pilastras con bolas que flanquean los vanos altos, por los huecos elipsoidales y, junto a todo ello, por el propio y sutil juego de geometrías pétreas que subrayan los abovedamientos de las crujías. Y sobre esto cabe afirmar que también son de una pulcra fidelidad a soluciones y formas que estaban solidamente asentadas en el ambiente meridional; hasta el punto que las sutiles geometrías recuerdan las de Ambrosio de Vico en ejemplos granadinos ${ }^{63}$, los tragaluces ovales formas derivadas de Andrés de Valdelvira ${ }^{64}$, las pilastras con bolas de los balcones soluciones de Herrera ${ }^{65}$ y la doble estructuración, una hibridada evocación de soluciones de Vandelvira - los muros internos de la Catedral de Jaén - y a la vez de Herrera según se puede apreciar, una vez más, en el frente de la iglesia de El Escorial.

\section{EL CLAUSTRO DE SAN MARTÍN Y EL DE LA CLERECÍA DE SALAMANCA}

Tal vez porque ambos recintos claustrales se encuentran en territorio español, porque son los dos singulares en el protagonismo que le otorgan a las columnas gigantes, porque hasta cierto punto están próximos en lo geográfico $\mathrm{y}$, sobre todo, porque el salmantino se vincula al hacer de un arquitecto que nació en Compostela como era el caso de Andrés García de Quiñones ${ }^{66}$, casi siempre ha sido habitual ponerlos en relación y supeditar

\footnotetext{
${ }^{63} \mathrm{Tal}$ es el caso de las torres de las iglesias de Iznalloz, de Almuñecar y la que también proyectó para Santa María de la Alhambra. Las tres son de principios del siglo XVII. Vid. GÓMEZ-MORENO CALERA (1992), 75-78.

${ }^{64}$ Presiden de hecho, el cuerpo-ático del Palacio Vázquez Molina en Ubeda. Asimismo formas ovales aunque sin horadar aparecen también en la Sacristía de la Catedral de Jaén y en los muros internos del cuerpo alto del patio del Palacio de Carlos V. Por cierto que esta referencia vandelviriana ya fue señalada en su momento por FOLGAR, 65.

${ }^{65}$ Sin olvidar que con una configuración básica muy parecida; esto es: Un balcón rectangular flanqueado de pilastras dóricas con un remate ornamental superior, todo dispuesto sobre un gran arco que preside su cuerpo bajo, aparece también en los lienzos murales que, entre semicolumnas gigantes adosadas a la pared, sirven para acotar y engalanar interiormente el espacio principal de la Catedral de Jaén debida a Valdelvira.

${ }^{66}$ Sobre este arquitecto véase RODRÍGUEZ G. DE CEBALLOS (1968, I), 35-43 y RODRÍGUEZ G. DE CEBALLOS (1968, II), 105-130.
}

"CUADERNOS DE ESTUDIOS GALLEGOS", Tomo XLI, Fascículo 106, Santiago 1993-94. 
la estructura del segundo, dada su cronología dieciochesca, al influjo del claustro santiagués ${ }^{67}$. Pues bien, sólo quedándonos en una primera impresión es posible afirmar tal parentesco una vez que, más allá de ciertas peculiaridades que para nada son decisivas, comprobamos que cada cual tiene su personalidad propia y, en concreto el de la Clerecía, además, unas fuentes y referencias arquitectónicas que nada tienen que ver con las señaladas para San Martín y en cambio mucho, desde mi punto de vista, con otras que son de raiz y difusión claramente exterior. En este sentido pienso que tenía razón Kubler cuando afirmaba que el patio salmantino poseía precedentes extranjeros y cosmopolitas aunque no esté con él en hacer de Bramante y en particular del Patio del Belvedere la fuente principal de referencia ${ }^{68}$. Sobre esta cuestión creo más bien que tiene más validez la opinión del padre Ceballos que atribuye al influjo de la obra grabada de Borromini muchas de las peculiaridades del patio de la Clerecía que, en efecto, no está del todo desligado de una relación con el Colegio de la Propaganda Fide de Roma ${ }^{69}$. Es más, ahondando en las raices italianas de la estructura salmantina, no dudaría también en señalar que junto a Borromini hubo asimismo otros influjos como el del patio del palacio vicentino Iseppo-Porto de Palladio que siempre apareció reproducido en casi todas las ediciones completas de su tratado de arquitectura y que, en efecto, deja ver una estructura columnaria muy parecida y en la línea de la que el mismo autor también desarrolló en la Loggia del Capitano. Junto a esto, además de la obra señalada por Ceballos, indicaría otra realización también muy significativa del propio Borromini como es el patio del Oratorio de San Felipe Neri de Roma. Y por último, aunque en lo decorativo quepa ver un cierto influjo español ${ }^{70}$, en la estructura pienso que no es del todo imposible el conocimiento del patio "palladiano" que Bernini, también con columnas corintias monumentales y doble cuerpo, organizó para el segundo proyecto del palacio del Louvre y que, como es sabido, nunca se llegó a ejecutar. En todo caso, no se puede negar que el proyecto berninesco tuvo un cierto eco y proyección públicas; ya que de otro modo no podría entenderse el patio que, con peculiaridades formales muy pare-

\footnotetext{
${ }^{67}$ Así lo han afirmado, entre otros, BONET, 157 y VILA (1993, I), 290.

${ }^{68}$ KUBLER, 199.

${ }^{69}$ RODRÍGUEZ G. DE CEBALLOS $(1968$, II), 114.

${ }^{70}$ En este sentido siempre se ha puesto en relación con el patio de Santo Tomás de Madrid de Jiménez Donoso.
}

"CUADERNOS DE ESTUDIOS GALLEGOS", Tomo XLI, Fascículo 106, Santiago 1993-94. 
cidas, Juvarra, en 1735, diseñó para el Palacio Real de Madrid que entonces se pensaba erigir en los altos de San Bernardino ${ }^{71}$.

Todo esto, creo yo, aunque no excluye que puedan existir otros influjos, apunta cuando menos a que el claustro de la Clerecía va en una dirección arquitectónica bien distinta a la que hemos dado para el patio de Lechuga. En Santiago era Bramante, Herrera y el mundo andaluz la tradición arquitectónica que estaba detrás ${ }^{72}$; en Salamanca, en cambio, Palladio, sin duda Borromini, quizás Bernini y hasta un cierto eco del mundo decorativo español tan grato a nuestro Barroco. Por consiguiente, no me parece apropiado hablar de semejanzas y relaciones creibles entre los dos patios referidos toda vez que, pese a las apariencias, se ha demostrado que tienen bien poco que ver entre sí en sus soluciones básicas. Sin duda cada uno es hijo de distintos influjos y por ello cada cual es, en sí mismo, modélico, único y hasta diría que ejemplar lo que enriquece con mucho la aportación española a la tipología de claustros que, por lo demás, cuenta en Europa con muchas e importantes realizaciones todas de altísimo valor.

\section{BIBLIOGRAFÍA}

ANDRADE, D.: Excelencias, Antigüedad y Nobleza de la Arquitectura, Santiago, 1695. Cit. por la edición facsímil publicada en Santiago en 1993 con comentarios de Miguel Taín Guzmán.

BARREIRO FERNÁNDEZ, J.R.: "Abadologio del monasterio benedictino de San Martín Pinario en Santiago de Compostela (1607-1835)", Studia Monástica, vol. 7, Montserrat, 1965, pp. 147-188.

BERNALES BALLESTEROS, J. ET AL.: El Arte del Barroco. Urbanismo y arquitectura, en $\mathrm{H}^{\mathrm{a}}$ del Arte en Andalucía, VI, Sevilla, 1989.

BERNALES BALLESTEROS, J. ET AL.: El Arte del Renacimiento. Urbanismo y arquitectura, en $\mathrm{H}^{\mathrm{a}}$ del Arte en Andalucía, IV, Sevilla, 1990.

BONET CORREA, A.: La Arquitectura en Galicia durante el siglo XVII, Madrid, 1966.

\footnotetext{
${ }^{71}$ Vid. PLAZA, 36 y ss. y GRITELLA, II, 439 y ss.

${ }^{72}$ Por las razones que se han argumentado no comparto, al menos en sentido demasiado estricto, el "palladianismo" que señalan VILA (1993, I), 290 y BUSTAMANTE, 48.
}

"CUADERNOS DE ESTUDIOS GALLEGOS", Tomo XLI, Fascículo 106, Santiago 1993-94. 
BONET CORREA, A.: Andalucía Barroca, Barcelona, 1978.

BUSTAMANTE GARCÍA, A.: El siglo XVII. Clasicismo y Barroco, Introducción al Arte Español, Madrid, 1993.

COLOMBAS, G.M.: Las señoras de San Payo, Santiago, 1980.

CRUZ VALDOVINOS, J.M.: Arquitectura Barroca. Siglo XVII, en $\mathrm{H}^{\mathrm{a}} \mathrm{de}$ la Arquitectura Española, IV, Barcelona, 1986, pp. 1219-1351.

FERNÁNDEZ REY, A.A.: "Varios siglos de actividad constructiva en San Martín Pinario", en Galicia no tempo. 1991, Santiago, 1991, pp. 349392.

FOLGAR DE LA CALLE, M 'C.: "Fernández Lechuga", Gran Enciclopedia Gallega, XII, pp. 65-68.

FOLGAR DE LA CALLE, Ma C.: "El proyecto de Bartolomé Fernández Lechuga para la capilla de Ntra. Sra. del Rosario en la iglesia de Santo Domingo de Bonaval de Santiago", en Los Caminos y el Arte, Actas del VI Congreso Español de Historia del Arte, II, Santiago, 1989, pp. 251-258.

FOLGAR DE LA CALLE, Ma C.: "Los conventos", en Santiago de Compostela, La Coruña, 1993, pp. 317-431.

GALERA ANDREU, P.: "Una familia de arquitectos jienenses: los Aranda", en Bol. Inst. Estudios Giennenses, 1978, pp. 3-13.

GARCÍA IGLESIAS, J.M.: Fernando de Casas Novoa, Santiago, 1993.

GARCÍA MERCADAL, J.: Viajes de extranjeros por España y Portugal, 3 vols., Madrid, 1952-1959-1962.

GARRIDO, G.A.: Aventureiros e curiosos. Relatos de viaxeiros estranxeiros por Galicia. Séculos XV-XX, Vigo, 1994.

GILA MEDINA, L.: Arte y artistas del Renacimiento en torno a la Real Abadía de Alcalá la Real, Granada, 1991.

GÓMEZ-MORENO CALERA, J.M.: La arquitectura religiosa granadina en la crisis del Renacimiento (1560-1650), Granada, 1989.

"CUADERNOS DE ESTUDIOS GALLEGOS", Tomo XLI, Fascículo 106, Santiago 1993-94. 
GÓMEZ-MORENO CALERA, J.M.: El arquitecto granadino Ambrosio de Vico, Granada, 1992.

KUBLER, G.: Arquitectura de los siglos XVII y XVIII, Ars Hispaniae, XIV, Madrid, 1957.

GRITELLA, G.: Juvarra. L'Architettura, II, Torino, 1992.

LABORDE, A.: Itinerario descriptivo de las provincias de España y de sus islas y posesiones en el Mediterráneo, Valencia, 1816.

LÓPEZ FERREIRO, A.: Historia de la Santa A.M. Iglesia de Santiago de Compostela, IX, Santiago, 1907.

LÓPEZ GUZMÁN, R.: Tradición y Clasicismo en la Granada del siglo XVI. Arquitectura y urbanismo, Granada, 1987.

LLAGUNO, E. y CEÁN BERMÚDEZ, A.: Noticias de los arquitectos y arquitectura de España desde su restauración, IV, Madrid, 1829. Cit. por nueva ed. de 1977.

MARÍAS, F.: "La arquitectura del Clasicismo en Galicia", en Galicia no tempo. 1991, Santiago, 1991, pp. 171-184.

MÉDICIS, C. DE: Viaje de Cosme de Médicis por España y Portugal (1668-1669), Madrid, s.a.

MORALES, A. DE: Viaje a los Reinos de León y Galicia y Principado de Asturias (1572). Cit. por la ed. de Oviedo, 1977.

MURGUÍA, M.: Galicia, I, Vigo, 1982, 1ª ed., en 1888.

ORTEGA ROMERO, $\mathrm{M}^{\mathrm{a}}$ S.: El Barroco, $\mathrm{H}^{\mathrm{a}}$ del Arte Gallego, Madrid, 1982, pp. 283-388.

PÉREZ COSTANTI, P.: Diccionario de artistas que florecieron en Galicia durante los siglos XVI y XVII, Santiago, 1930.

PITA ANDRADE, J.M.: La arquitectura española del siglo XVII, Summa Artis, XXVI, Madrid, 1982, pp. 427-634.

PLAZA SANTIAGO, F.J.: Investigaciones sobre el Palacio Real nuevo de Madrid, Valladolid, 1975.

"CUADERNOS DE ESTUDIOS GALLEGOS", Tomo XLI, Fascículo 106, Santiago 1993-94. 
RODRIGUEZ G. DE CEBALLOS, A.: (1968, I) "Noticias sobre el arquitecto Andrés García de Quiñones", Archivo Español de Arte, Madrid, 1968, pp. 35-43.

RODRIGUEZ G. DE CEBALLOS, A.: (1968, II) "La Arquitectura de Andrés García de Quiñones, Archivo Español de Arte, Madrid, 1968, pp. 105-130.

ROSENTHAL, E.E.: El palacio de Carlos V en Granada, Madrid, 1988.

SA BRAVO, H.: El Monasterio de San Martín Pinario, León, 1988.

DOMENICO SCARLATTI EN ESPAÑA. Utopía y realidad en la Arquitectura, Madrid, 1985.

SCHUBERT, O.: Historia del Barroco en España, Madrid, 1924.

VIGO TRASANCOS, A.: "La iglesia monástica de San Martín Pinario en Santiago de Compostela. Proyecto, fábrica y artífices", Compostellanum, Santiago, 1993, pp. 337-362..

VIGO TRASANCOS, A.: (1994) "Sobre el arquitecto portugués Mateo López, la iglesia monástica de San Martín Pinario y el Clasicismo en Compostela (1590-1605)", en Los Clasicismos en el Arte. Actas del X Congreso Español de Historia del Arte, Madrid, 1994, pp. 327-335.

VILA JATO, M ${ }^{\mathrm{a}}$ D.: "San Martiño Pinario en su acontecer pasado: El esplendor de un monasterio", Galicia no tempo, Santiago, 1990, pp. $69-79$.

VILA JATO, Ma D.: (1993, I) "Los grandes centros monacales", en Santiago de Compostela, La Coruña, 1993, pp. 265-315.

VILA JATO, Mª D.: (1993, II) Galicia en la época del Renacimiento. La Arquitectura, en Galicia. Arte, XII, La Coruña, 1993.

VILA JATO, Ma D.: (1994) "Precisiones sobre la construcción del monasterio de San Martín Pinario de Santiago", en Tiempo y Espacio en el Arte. Homenaje al prof. A. Bonet Correa, I, Madrid, 1994, pp. 449459.

"CUADERNOS DE ESTUDIOS GALLEGOS", Tomo XLI, Fascículo 106, Santiago 1993-94. 